\title{
APROXIMACIÓN A LA FIGURA DEL DISCUSSOR
}

\author{
María José Azaustre Fernández \\ Universidad de Oviedo, Espanha \\ azaustremaria@uniovi.es
}

RESUMEN: Este trabajo analiza el régimen jurídico de los discussores, funcionarios presentes a partir del Bajo Imperio, a quienes correspondían tareas de inspección e intervención fiscal, entre otras recogidas en las fuentes. Se examinan aquí sus principales derechos y obligaciones y las medidas establecidas por la normativa imperial para prevenir y sancionar eventuales abusos. En el último apartado se analiza brevemente la pervivencia de estos funcionarios en el Imperio Bizantino y en algunos de los reinos que sucedieron a la caída del Imperio Romano de Occidente. PALABRAS CLAVE: Corrupción. Derechos del contribuyente. Discussor. Logotheta.

\section{An approach to the figure of the discussor}

\begin{abstract}
This papers analyzes the legal regime of the discussores, officials present since the Later Empire, whose tasks were mainly of tax inspection and intervention, among others collected in the sources. Their main rights and obligations and the measures established by imperial regulations to prevent and sanction possible abuses are examined here. In the last section it is briefly analyzed the survival of these officials in the Byzantine Empire and in some of the kingdoms that followed the fall of the Western Roman Empire.
\end{abstract}

KEYWORDS: Corruption. Taxpayer rights. Discussor. Logothete.

\section{Aproximação à figura do discussor}

RESUMO: Este trabalho analisa o regime jurídico dos debatedores, funcionários públicos presentes do Baixo Império, que estavam encarregados das tarefas de inspecção e intervenção fiscal, entre outras incluídas nas fontes. Os seus principais direitos e obrigações são aqui examinados, bem como as medidas estabelecidas pelos regulamentos imperiais para prevenir e punir possíveis abusos. A última secção analisa brevemente a sobrevivência destes funcionários no Império Bizantino e em alguns dos reinos que se seguiram à queda do Império Romano Ocidental.

PALAVRAS-CHAVE: Corrupção. Direitos do contribuinte. Discussor. Logotheta 


\section{INTRODUCCIÓN}

En general, la palabra discussor suele ser entendida como sinónimo de persona que investiga, inspecciona, revisa o discute ${ }^{1}$. En las fuentes romanas se aprecia este sentido en Macrobio $^{2}$, que emplea el término discussor en alusión a quien examina o escruta y en Símaco ${ }^{3}$, que lo considera como un inspector, verificador o revisor de cuentas. También en la glosa de Accursio ${ }^{4}$ se afirma que por discussor habría que entender "el que razona o discute".

Advierte Pergami ${ }^{5}$ que la posición y las tareas de este funcionario resultan extremadamente inciertas. No obstante, ya desde antiguo se ha asociado su labor a la inspección fiscal ${ }^{6}$. De este modo, Godofredo ${ }^{7}$ entiende que se trata de aquellos enviados a provincias con carácter extraordinario para examinar, indagar, inspeccionar o inquirir si se habían pagado las deudas de los impuestos en su totalidad o sí había demoras en el cobro de los atrasos, advirtiendo contra el error de quienes los confunden con los exactores ordinarios. Para Cuiacio ${ }^{8}$ los discussores son

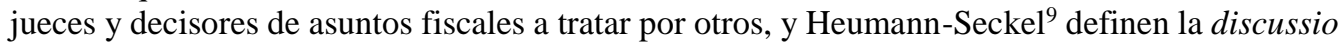

1 Sobre este tema puede destacarse la siguiente bibliografía: ACCURSIUS, Glossa in Volumen, Corpus Glossatorum Juris Civilis, Augustae Taurinorum, 1969, p. 344; GothOFREDI, I. Codex Theodosianus, t. IV, Lipsiae, 1740; CuJACII, J., Opera ad parisiensem fabrotianam editionem, in XIII t. distributa, t. X, Prati, 1840, p. 94; BoUCHARD, L., Étude sur l'administration des finances de l'Empire Romain dans les dernier temps de son existence, Librairie de Guillaumin, Paris, 1871; CuQ, E. L'Examinatio per AEgyptum, Mélanges d'archéologie et d'histoire, t. 13, 1893, p. 21 y ss., y Études d'epigraphie juridique. De quelques inscriptions relatives à l'administration de Dioclétien, Bibliothèque des écoles françaises d'Athènes et de Rome, E. Thorin, Paris, 1881; SEECK, voz “discussor”, Paulys Realencyclopädie der classischen Altertumswissenschaft, neue Bearbeitung, I-5, Alfred Druckenmüller, Sttutgart, 1970;_HUMBERT, G., Saggio sulle finanze e sulla contabilità pubblica presso i romani, trad. it. E. D'Errico, Arnaldo Forni Editore, Bologna, 1977 (ed. facsim. de la de 1886); MonKS, G.R., "The Administration of the Privy Purse. An Inquiry into Official Corruption and the Fall of the Roman Empire", Speculum, vol. 32, no 4, 1957, p. 748 y ss.; Collot, C., "La pratique et l'institution du "suffragium" au Bas-Empire", Revue du Histoire et Droit française et étranger, 43, 1965; THOMSON, E. A., Los godos en España, trad. Javier Faci, Alianza Editorial, Madrid, 1971; APARICIO PÉREZ, A., La Hacienda Pública en el Bajo Imperio Romano (años 284 a 476 d. C), Dykinson, Madrid, p. 500; JonES, A.H.M., The Later Roman Empire (284-602). A social, economic and administrative survey, Basil Blackwell, Oxford, 1964; DELMAIRE, R. Les responsables des finances impériales au Bas-Empire romain (IVe-VIe s.) Études prosopographiques, 1989; Pergami, F., L'appello nella legilazione del tardo Imperio, Giuffrè ed., Milano, 2000, p. 360; QUINTANA ORIVE, E., Régimen jurídico de la responsabilidad de los funcionarios en Derecho romano, 2013, disponible en digitool-uam.greendata.es (consultado el 22 de noviembre de 2019); AGUDO RUIZ, A., "La apelación fiscal en la legislación imperial del Codex Theodosianus", en Estudios de Derecho fiscal romano, Dykinson, Madrid, 2016; TRISCIUOGLIO, A., Studi sul crimen ambitus in età imperiale, Ledizioni, Milano, 2017; MARTínEZ VELA, J.A., Varias notas sobre la responsabilidad en Derecho romano del personal encargado de la gestión tributaria, Documento de trabajo Seminario Permanente de Ciencias Sociales, https://www.uclm.es/-/media/Files/C01-Centros/cu-csociales/documentos2012/4.ashx?la=en; LEMKE, L., Bridging Center and Pefiphery: Administrative Communication from Constantine to Justinian, Mohr Siebeck, Tübingen, 2020.

2 Macrobio, Commentarii in Somnium Scipionis, 1,21,8: Hoc loco diligens rerum discussor inveniet quod requirat

3 Symm., Epistulae, 4, 70 y 5, 76

4 Accursius, Glossa in Volumen, "Corpus Glossatorum Juris Civilis”, Augustae Taurinorum, 1969, p. 344 gl. g/ a Rubrica. De discussoribus.

PERGAMI, op. cit., p. 360.

6 Cfr. Blánquez Fraile, A., Diccionario latino-español, $5^{\mathrm{a}}$ ed., Ramón Sopena, 1960, t. I, voz «discussor», p. 584. Según el Lexicon Iuridicum Romano Teutonicum, Nunberg, 1736, p. 224, discussor es el que comprende las cuentas (der die Rechnung verstehet); según AINSWORTH, R., Thesaurus Lingua Latinae Compendiarius London, 1752, es un explorador o investigador (explorer, investigator). ERNOUT A.-MEILLET, A., Dictionnaire étymologique de la langue latine. Histoire des mots, Klinksieck, Paris, 2001, p. 552 -voz «quatio»- afirman que en la cancillería del Bajo Imperio la discussio designa la revisión de los ingresos públicos en una provincia, mientras que el discussor sería el magistrado encargado de la revisión.

7 GOTHOFREDI, op. cit., p. 194: erant scil. Qui in prouincias extra ordiuemmittebantur, examinaturi, indagaturi, inspecturi, inquisituri (vunde Discussionis examen, indago, inquisitio) quid tributorum nomine exactum esset, quid in Reliquis resideret, quique adeo prouinciales ad Reliquorum solutionem cogerent.

8 CUJACII, op. cit., p. 94: discussores sunt veluti cognitores et disceptatores rationum fiscalium ab aliis tractatarum.

9 HeumanN-SECKEL, Handlexikon zu den Quellen des römischen Rechts, G. Fischer ed., Jena, 1926, p. 151. 
como la función de distintos funcionarios imperiales, los discusores, revisores de cuentas, a los cuales correspondía examinar las cuentas de los aranceles y obras públicas.

De estos funcionarios tenemos conocimiento, de un lado, gracias a los testimonios que aparecen en diversas fuentes literarias y que se analizarán en la primera parte del trabajo. Por lo que se refiere a las fuentes epigráficas, se ha referido la mención de un discussor en una inscripción fragmentaria en Nessana, datada en el reinado de Justiniano en algún momento anterior al 548 , en la que se mencionaría un recibo entregado tras haber confirmado un pago de impuestos ${ }^{10}$.

Como principales fuentes jurídicas hay que destacar las rúbricas De discussoribus que se encuentran tanto en el Código Teodosiano (CTh. 11,26) como en el de Justiniano, además de referencias dispersas a lo largo de ambos Códigos: se trata de C.Th. 8,15,5,1; CJ. 1, 4, 26; CJ. 2,7,6; CJ. 7,55,7, CJ. 8,13 (12),1, pr. y CJ. 11,57,6 y CJ. 12, 7,1 fundamentalmente. También hay que tener en cuenta la Novela Th. 22,1,1, del año 442 d.C. y, sobre todo, la Novela de Valentiniano III 1, 3, del año 450 d.C. La figura no aparece, sin embargo, recogida en la Notitia Dignitatum, ni para la parte oriental ni para la parte occidental del imperio.

En este trabajo se tratará de trazar unas líneas generales para sistematizar la regulación correspondiente a estos empleados públicos, tratando de indicar cuáles eran las funciones que se les podían encomendar, cuáles eran sus derechos y obligaciones, qué medidas se establecían para prevenir sus posibles abusos, así como el régimen de sanciones previsto para castigar las infracciones que pudieran cometer en el ejercicio de su cargo. En el último apartado se tratará de seguir la huella de los discussores tras la caída del Imperio romano de Occidente.

\section{LA FIGURA DEL DISCUSSOR EN LAS FUENTES LITERARIAS}

Por regla general, las fuentes literarias trasmiten una imagen bastante negativa de los discussores, denominados en griego logotetas ${ }^{11}$, quienes aparecen como funcionarios dispuestos a toda clase de abusos sobre los contribuyentes. Sin embargo, no debe perderse de vista que tampoco serían los únicos funcionarios que cometían abusos, y así, es posible encontrar en la legislación bajoimperial bastantes ejemplos de normas que tratan de poner freno a las concusiones de diversos empleados públicos ${ }^{12}$.

${ }^{10}$ Di SEgni, L. "Metropolis and Provincia in Byzantine Palestine", Caesarea Maritima: a retrospective after two millennia, ed. Avner Rabban- Kenneth G. Holum, Leiden-New York-London, 1996, p, 585 n. 52, localiza tal inscripción en la obra de Kirk-Welles, “The Inscriptions”, H. D. Colt ed., Excavations at Nessana I London, 1962, pp, 174-5.

${ }^{11}$ Sobre la etimología y significado de la palabra "logoteta", cfr. SEMENOV, A., «Über Ursprung und Bedeutung des Amtes der Logotheten in Byzanz», Byzantynische Zeitschrift, 19 (1910), p. 441-442; para quien la palabra deriva del

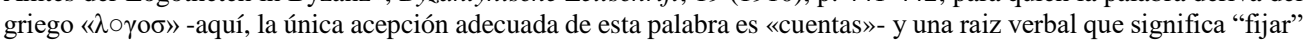
o "determinar". Por tanto, el logoteta sería el funcionario para la redacción de cuentas o informes financieros. De Procopio, Bell. Goth., 3,1 concluye que este funcionario tenía su equivalente, con su correspondiente nombre en latín, en época romana.

12 Vid., a título de mero ejemplo, y ciñéndonos únicamente a la administración fiscal y no a otros sectores de la administración, C.Th. 13,11, y CJ. 11, 58,5 en relación a los peraequatores o repartidores de las cargas de los censos; CJ. 10,20,1 en referencia a los curiales, cohortales y otros exactores; CJ. 12, 62 (61), dedicado a los lucros de los abogados y las concusiones de los oficiales o alguaciles - de lucris advocatorum et concussionibus officiorum seu apparitorumetc. Refleja también muy claramente la corrupción de la administración fiscal la Nov. II de Mayorano. Respecto a los canonicarii -enviados por el Praefectus Praetorio a revisar la actividad financiera de los gobernadores provinciales puede verse APARICIO PÉReZ, A, La Hacienda Pública en el Bajo Imperio...cit., p. 257. En relación con los abusos en materia tributaria cometidos por los gobernadores provinciales y los exactores -cobradores de impuestos-de sus oficinas, vid. QUINTANA ORIVE, E., «"Ne damna provincialibus infligantur”: Algunas observaciones sobre la protección de la población rural en la legislación de época postclásica y justinianea», $R G D R, 32,2019$, p. 3 y ss. Sobre la corrupción en la administración fiscal en general cfr. JONES, A.H.M., The decline of the ancient world, Longman, London, 1975, p. 175 y ss., MONKS, op. cit., p. 761 y ss., COLlOT, op. cit., p. 185 y ss. 
Aparte del clima de corrupción existente en el Bajo Imperio como consecuencia de la crisis política, social y económica ${ }^{13}$, quizás un factor -aunque, desde luego, no el único- que pudo haber contribuido a las conductas reflejadas en las fuentes haya sido la forma en la que estos funcionarios recibían su retribución, consistente en un porcentaje (una doceava parte) de lo recuperado para el fisco. Este sistema debía de estimular la actividad recaudatoria de los discussores y resultar ventajoso para el fisco, como observa Procopio de Cesarea ${ }^{14}$. Las disposiciones imperiales nunca llegaron a alterar este régimen de retribución, por lo que muchas de las medidas encaminadas a frenar los excesos, y que se van repitiendo por los sucesivos emperadores- debieron de resultar, a la postre, poco eficaces, a juzgar por la forma en la que estos personajes siguen siendo retratados en las sucesivas fuentes.

Las referencias literarias a los discussores se encuentran, fundamentalmente, en las obras de Símaco y de Procopio de Cesarea -tanto en sus Guerras como en la Anécdota o Historia Secreta-. También se recogen algunas menciones en las obras de Corippius ${ }^{15}$, Iuvencio ${ }^{16} \mathrm{y}$, ya en relación con el reino ostrogodo, en las Epistulae o Variae de Cassiodoro.

Por lo que se refiere a Símaco, en sendas cartas fechadas en el 387 y dirigidas respectivamente a Eusignio, Prefecto del Pretorio de Italia e Ilírico en los años 386-387 y a Licinio, Comes Sacrorum Largitionum $^{17}$, se queja de que, habiéndose encomendado la inspección de las cuentas de la Basílica y el puente al gobernador Bonoso, hombre recto y capaz de llevar a cabo hasta el final la investigación encomendada, se haya admitido como colega para tal tarea al comes e ingeniero Ciríades, que había tenido en sus manos los gastos para tales obras. La rivalidad entre ambos había entorpecido el curso de las investigaciones, por lo que Símaco, temiendo un encubrimiento de una enorme pérdida de fondos públicos como consecuencia de tal obstaculización,

${ }^{13}$ COLlot, op. cit., p. 185.

${ }^{14}$ Sobre la credibilidad de Procopio vid. Pulliati, S., Ricerce sulla legislacione "regionale” dei Giustiniano, 1980, p. 15, n. 24, así como la bibliografía que cita en la n. 19. Para el jutista italiano el juicio valorativo de Procopio está influido por su conservadurismo, por sus motivaciones religiosas - profesaba el arrianismo- y políticas en favor de la clase senatorial. Para SIGNES CORDOÑER, J., "Introducción" a la Historia Secreta de Procopio, Biblioteca Clásica Gredos, 279, Madrid, 2000, p. 90 y ss., "la parcialidad y la distorsión de los hechos que predominan en esta obra resultan del deseo de demostrar mediante un apabullante repertorio de catástrofes e iniquidades su juicio apocalíptico sobre el reinado de Justiniano; lo que no es óbice para que se aprecie en Procopio un esfuerzo constante de documentación y veracidad detrás de cada noticia", pues "las informaciones de Procopio proceden, por lo general, de primera mano y es solo la distorsión final de su mensaje la que ha impedido dar crédito a muchas de ellas frente a las que nos proporcionan otras fuentes". Neville Ure, P., Justiniano y su época, trad. Sela Hoffman, E. Revista de Derecho Privado, Madrid, 1963, p. 197, 203 y ss., no duda de la honestidad y veracidad de Procopio cuando escribía objetivamente acerca de los acontencimientos de los que había sido testigo o podía tener certeza a través de testigos oculares. En cambio, el interés de su Historia Secreta es principalmente subjetivo o incluso -precisa- patológico, lo que no impide reconocer el valor de la obra como depósito suplementario de posibles hechos. La evolución de este historiador la explica como consecuencia de su decepción al comprobar que las empresas justinianeas no habían alcanzado los espléndidos resultados que prometían en sus comienzos, y del sentimiento de impotencia ante el despotismo intelectual y político bajo el que vivía. Sobre la necesidad de relativizar la información que ofrecen las fuentes literarias en general, RodRÍGUEZ LÓPEZ, R.-GUIJARRO, R., “El ius fiscale en el Imperio Protobizantino”, RIDROM, n 7, 2011, p. 93.

${ }^{15}$ CORIPPIUS, In laudem Justini minoris 1, 24 menciona entre las personas que le apremian para la conclusión de su obra a Magno, que se ocupa de las cuentas sagradas y es quien controla -discussor- a los dirigentes del imperio latino: ...nec non magnanimus meritis et nomine Magnus, mente placens dominis, sacris rationibus aptus, rectorum Latii discussor providus orbis

${ }^{16}$ IUVENCIUS, Historiae evalengicae, 1,179: Sed tum forte novi capitum discussio census Caesaris Augusti iussis per plurima terrae descrivevatur, syriam quun iure regebat Cyrinusm, proprios cui tota per oppida fines edebant populi, vires, nomenque, genusque. En la edición anotada de Villagómez Lorenzana, Roma, 1792, p. 90, se recoge la explicación que hace Barthius de este pasaje, distinguiendo entre el censo efectuado en tiempos de Augusto -recensio populorum- y la discussionem novi censum. La discussio sería, de acuerdo con Barthius, el oficio de los discussores, a saber, inspectoris, censoris aut quaestoris, pues la discussio es inspectio, censio, census, diligentior examinatio, scrutatio.

${ }^{17}$ Symm., Epistulae, 4, 70 y 5, 76. La obra a la que se refieren estas cartas es la segunda Basílica de S. Pablo Extramuros. 
solicita que se den facultades a un inspector único para la conclusión de tal tarea. Se ha destacado que la actividad de Bonoso en este episodio histórico no fue el correspondiente al lado económico de las obras, sino el de responsable de la encuesta realizada sobre este aspecto financiero ${ }^{18}$. Puede observarse como en el pasaje de Símaco resultan contrapuestas las conductas de los dos discussores, Bonoso y Ciríades.

Por su parte, Procopio describe la corrupción de los logotetas ${ }^{19}$ enviados por Justiniano a Italia $^{20}$. Víctimas de sus prácticas resultaban, en primer lugar, los soldados. El sistema determinaba el incremento de su paga a medida que se cumplían años de servicio y se ascendía en el orden de los registros ( $\kappa \alpha \tau \alpha \lambda o \gamma o \sigma)$. Pero los logotetas no permitían la eliminación de los nombres de los fallecidos de dichos registros, por lo que los soldados que sobrevivían quedaban bloqueados, recibiendo una parte que estaba muy por debajo de su rango, mientras los logotetas se repartían con Justiniano el dinero de los soldados. No contentos con esto, acusaban falsamente a algunos de estar enrolados sin permiso del emperador, tachando de falsas las órdenes imperiales que los soldados les exhibían, al tiempo que acusaban a otros de haber abandonado algunos días a sus compañeros. Indica Procopio que incluso los ayudantes de los generales sufrieron las consecuencias de la actuación de estos funcionarios, padeciendo hambre y miseria extremas. ${ }^{21}$

También acusa a los logotetas, en particular a un tal Alejandro, apodado por los bizantinos "el Tijeras"22, de promover una fiscalización totalmente injustificada contra los italianos, acusándolos de haber tratado injustamente a Teodorico y al resto de generales godos, pese a que en ningún momento habían tocado el fisco imperial ni cometido ninguna irregularidad en la hacienda pública ${ }^{23}$.

${ }^{18}$ MARTínEZ-FAZIO, L.M., "Reciente hipótesis sobre la fundación de la Basílica Ostiense”, Gregorianum, 58-1, 1977, p. 97.

19 Muchos autores identifican los logotetas del Imperio Bizantino con los discussores del Imperio romano; en este sentido cfr. Godofredo, Codex Theodosianus, t. IV, cit., p. 194; CUJACII, t. 10, cit., p. 94, SEECK, op. cit., p. 1183. En contra, existen autores que encuentran en otros funcionarios romanos, como los numerarii o los rationalis los antecedentes de los logotetas griegos. Vid. infra, nota 128.

${ }^{20}$ Procopio De Cesarea, Historia Secreta, 18,15, trad. Signes Cordoñer, ed. Biblioteca Clásica Gredos, 279, Madrid, 2000, p. 263: "Todos los errores que cometió (Justiniano) en Libia, los repitió también allí (en Italia). Después de enviar a los llamados logotetas no tardó nada en destruir y arruinarlo todo".

${ }^{21}$ Ibidem, 24,1-2. Sobre este episodio vid. GuILLAND, R., «Les logothètes: Ėtudes sur l'histoire administrative de l'Empire byzantin», Revue des études byzantines, 29, 1971, p. 25.

${ }^{22}$ Refiere Procopio el origen de dicho apodo, que proviene de la habilidad de este personaje para cortar en círculo una moneda de oro para hacerla tan pequeña como quisiera, aunque conservando la misma forma redonda que tenía al principio, siendo "tijeras" el nombre que daban al instrumento para dicha tarea.

${ }^{23}$ Procopio, BG, 3,1,28 y ss. Explica JONES, op. cit., vol. I, p. 289 que en el 544 Belisario llega a Roma con cuatro mil hombres reclutados en Tracia, pero sin conseguir grandes resultados. Tras la caída de Rávena en el 540, Justiniano esperaba que Italia fuera capaz de sufragar los gastos por sí misma, por lo que no destinó dinero para pagar a las tropas y envió al discussor Alejandro a efectuar una auditoría, quien causó gran descontento entre los italianos, al actualizar demandas que databan de la época de la dominación ostrogoda. También descubrió y explotó irregularidades en la cuenta del regimiento, provocando gran descontento entre las tropas, desmoralizadas por llevar varios años de retraso en sus pagas, por lo cual muchos desertaron. Las fuerzas de Belisario se vieron además reducidas por la marcha de las unidades transferidas del ejército del Ilírico al mando Itálico que, quejándose de no haber recibido la paga durante tres años y de que pesaba sobre sus familias en Ilírico el peligro de las invasiones bárbaras, se amotinaron y marcharon a sus antiguos cuarteles (Proc. BG. 3,10, 1-2; 3,1, 28-33; 3.11.13-15). EvANS, J.A.S., The Age of Justinian. The circumstances of imperial power, Routledge, London-New York, 1996, p. 153 y 199, resume la actuación de Alejandro en Italia señalando que recaudó los impuestos sin piedad y recortó los costes del ejército, estrangulando a las tropas -que a su vez saquearon a los particulares- y a los italianos; enriqueciéndose tanto a sí mismo como al tesoro público. Sin respetar la tradición, barrió la oficialidad de la corte imperial occidental, redujo el status de la clase senatorial italiana y aceleró la decadencia del senado. La pista del personaje se pierde tras la derrota sufrida a manos de Totila en el 541 . 


\section{NATURALEZA Y FUNCIONES}

Las fuentes jurídicas atribuyen a los discussores tareas de diferente naturaleza. Ya Accursio registraba hasta siete sentidos distintos del término ${ }^{24}$. En general, se destacan las tareas de intervención e inspección tributaria ${ }^{25}$, llamando la atención también algunos autores sobre otras tareas jurisdiccionales en materia fiscal ${ }^{26}$.

Explica $\mathrm{Cuq}^{27}$ que no debe sorprender la reunión en manos de una misma persona de atribuciones tan diversas, pues la distinción existente en la actualidad entre el poder ejecutivo y judicial era desconocida tanto en la antigüedad como en el antiguo régimen.

El término discussor se aplica, como señala Seeck, a funcionarios de muy distinto tipo, que presentan como nota común el carácter extraordinario de su nombramiento ${ }^{28}$ y el de desempeñar tareas de alguna manera relacionadas con la comprobación de cuentas o valoraciones. A partir del testimonio de Símaco, Cuq añade un tercer rasgo característico: el de tratarse de personas de alta condición social ${ }^{29}$.

En cuanto a los antecedentes de esta figura, a juicio de $\mathrm{Cuq}^{30}$, la figura del discussor del Código Teodosiano guarda una importante analogía con la figura del examinator per Italiam $^{31}$. Caracteriza al primero como un funcionario existente a fines del siglo cuarto que actuaba como agente extraordinario del emperador y cuya misión consistía en examinar, indagar e investigar la gestión de dinero público. Añade que frecuentemente actuaba como delegado en dos casos bien distintos: para controlar el empleo de dinero destinado a obras públicas (CJ 8,12,1, pr) y para examinar los listados del impuesto y exigir el pago de los atrasos -reliqua-.

Las funciones que se asignan en las fuentes a los discussores son, fundamentalmente, las siguientes:

\footnotetext{
${ }^{24}$ ACCURSIUS, op. cit, p. 344; gl. g/ a Rubrica. De discussoribus.
}

25 Aparicio PéreZ, A., La Hacienda Pública en el Bajo Imperio Romano (años 284-476 d.C.), Dykinson, Madrid, 2012, p. 293, 295, y 500, que no duda en encuadrarlos entre los funcionarios encargados de la inspección, es decir, de las actividades de comprobación de elementos y circunstancias con trascendencia tributaria y de vigilancia del exacto cumplimiento de los deberes fiscales. En nuestro país, las funciones comprendidas dentro de la inspección tributaria están enumeradas en el artículo 141 de la Ley 57/2003, de 17 de diciembre, General Tributaria; al tiempo que el artículo 2.2 del R.D. 2188/1995, de 28 de diciembre, por el que se desarrolla el régimen del control interno ejercido por la Intervención General de la Administración del Estado, especifica cuales son las actividades incluidas dentro de la función interventora de la Administración pública.

${ }^{26}$ Así, Pergami, F., L'appello nella legilazione del tardo Imperio, Giuffrè ed., Milano, 2000, p. 360; AGUDO RUIZ, op. cit., p. 217.

${ }^{27}$ CUQ, Études...cit., p. 55.

${ }^{28}$ MonKS, op. cit., p. 764 también destaca el carácter extraordinario de estos funcionarios, que encuadra dentro de los palatini, funcionarios pertenecientes bien al Comitem Sacrorum Largitionum bien al Comitem Rerum Privatarum (Cfr. Du CANGE, Glossarium mediae et infimae latinitates, t. 6, col. 107a, Niort, 1883-1887)

29 Cfr. CuQ, E., Études...cit., p. 51 para quien el discussor comparte con el examinator, que le serviría de antecedente, su calidad de personaje de alta condición, un comes del emperador, el carácter extraordinario de su misión y la naturaleza de su función de examinare. SEECK, op cit., p. 1183 indica que en algunos casos se le daba la dignidad de conde, señalando como ejemplo los supuestos contemplados en CTh. 9,26,4, relativo a la pena por aspirar a la iteratio en determinados cargos, entre ellos, el de conde-comes- encargado de las investigaciones fiscales y Cass. Var. 3,25, que recoge una carta de Teodorico al discussor Simeon, vir illustris y comes.

${ }^{30}$ CuQ, Études...cit. p. 8 y 53 y ss.

${ }^{31}$ Como indica CuQ, Études...cit., p. 6, y L'Examinatio...cit., p. 21, la figura del examinator per Italiam no aparece recogida ni en el Código Teodosiano ni en la Notitia. Se contempla en la inscripción en la que está grabado el cursus honorum de Caelio Saturnino (CIL, I, 1704). También encuentra una mención en Fr. Vat., 292, que recoge una constitución del año 295 donde los emperadores Diocleciano y Maximiano ordenan acudir ante el corrector en un asunto relativo a una convalidación mortis causa de una donación efectuada de un padre a un hijo, el cual en los exámenes in examinationibus- dará a conocer esa sentencia que le haya dictado la razón del derecho y la equidad. 
1. La inspección fiscal, quizá la más relevante de entre las funciones desempeñadas por estos funcionarios $^{32}$. Efectivamente, los discussores eran enviados a las provincias -bien por el Prefecto Pretorio, bien por el mismo emperador, dependiendo de la época- con dos tipos de tareas distintas ${ }^{33}$ :

- controlar las cuentas, tanto del recaudador general como de los tabularios de la ciudad y de la provincia. Esta labor suponía una inspección extraordinaria, pues correspondía a los superiores jerárquicos de cada servicio la realización de inspecciones periódicas ${ }^{34}$

- controlar y compeler a los contribuyentes morosos que no han justificado el pago del impuesto o que han justificado pagos inexactos.

Esta última tarea queda reflejada, entre otros textos, en la Nov. Val. 1,3,2-5, del año $450^{35}$ :

Discussores ad provincias non electi, sicut conperimus, sed ambientes ire dicuntur, quod nobis et proceribus nostris aliarum sollicitudinum mole constrictis efficere inveniuntur otiosi. Hoc modo facultates possessorum miserabiliter conciderunt: et hinc maius incommodum, unde remedia certa debuere provenire. Ubi trepidam provinciam talis discussor adierit stipatus calumniarum ministris, superbit elatus inter obsequia sumptuosa, expetit adminicula provincialis officii, scholares etiam saepe coniungit, multiplicato et hominum numero et officiorum, ut, quantum avaritiae libuerit, terror extorqueat.

El propósito del emperador, según aparece en la constitución, es tratar de poner freno a las corruptelas de discussores que no habían sido elegidos en debida forma, sino que habían comprado su cargo ${ }^{36}$, y que, según relata, atemorizaban a la provincia, buscando el apoyo de la plantilla local, vinculando a sus servicios a los scholares, de modo que, multiplicando tanto el

${ }^{32}$ La doctrina española destaca la importancia de esta tarea, tomándola como punto de partida para definir a los discussores; así APARICIO PÉREZ, op. cit., p. 500, los considera como agentes encargados de controlar y presionar a los contribuyentes morosos, ejerciendo, también, en ocasiones, labores de vigilancia fiscal; QUINTANA ORIVE, op. cit., p. 515 y 690 se refiere a ellos como inspectores del Fisco y MARTínEZ VELA, op. cit, p. 16 señala que se dedicaban a inspeccionar el estado de las finanzas y obras públicas.

${ }^{33}$ HuMBerT, op. cit., p. 289 y 399; APARICIO PÉREZ, op. cit., p. 295. Define este autor la inspección fiscal como "las actividades y funciones desempeñadas por diversos agentes fiscales cuya finalidad es la de comprobar elementos y circunstancias con trascendencia tributaria, así como vigilar el exacto cumplimiento de los distintos deberes fiscales" (op. cit., p. 293).

${ }^{34}$ Cfr. Humbert, op. cit., p. 399. En CTh. 8.8.9 (= CJ., 12, 60,3) se recoge una constitución de Honorio y Teodosio en la que ordenan que cualquier persona enviada desde el departamento del Praefecto del Pretorio, del del Comes sacrorum largitionum o de cualquier otro para la exacción de un servicio obligatorio, vuelva en el plazo de un año ante el superior que lo haya enviado para mostrar pruebas de su eficiencia, indicando los impuestos que han sido recaudados como consecuencia de su actividad, lo que considere que se debe, en qué casos hay desbalance y quien es el culpable de que algo haya quedado sin pagar en dicha provincia: Idem aa. Palladio praefecto praetorio. Sive ex praetoriano officio sive illustris comitivae sedis largitionum nec non et rei privatae nostrae vel ex quacumque apparitione ad quamcumque necessitatem profligandam quis fuerit destinatus, sciat intra anni metas debere collectis ratiociniis ad proprium iudicem remeare eique suam efficaciam ostendere, quid eius instantia exactum fuerit quidve in debitis habeatur vel penes quos resederit vel cuius culpa aut causa in eadem provincia fuerit derelictum.). Entre las actividades de supervisión ordinaria, HUMBERT se refiere, entre otras, a la practicada por el Gobernador en relación a la recaudación de la annona; la del Comes Sacrorum Largitionum en relación a los tributos físcales (CTh. 12,6,11); añadiendo que los Gobernadores debían presentar sus cuentas al Vicario, quien vigilaba mensualmente y era responsable de los retrasos de los Gobernadores.

${ }^{35}$ La ley está fechada en Roma, el 5 de marzo de 450; pero en la propia subscriptio se dice que fue leída ante el Senado por el Ilustre Proconsul Postumiano el día 14 del mismo mes.

36 Advierte Collot, op. cit., p. 215, que, aunque sin emplear el término, nos encontramos ante un supuesto de suffragium, es decir, de la adquisición de un cargo a través de una recomendación retribuida, cuya factura acaban pagando los contribuyentes de provincias. El mismo término es utilizado por CUIACIO, op. cit., col. 95 (ad CJ. 10,30,2). Advierte MONKS, op. cit., p. 764 que normalmente estos funcionarios serían nombrados regularmente y que nadie desearía hacerse cargo de una tarea tan odiosa, pero que en la confusión administrativa y en el desorden de la crisis del Bajo Imperio las personas estaban deseosas de asegurarse una plaza de funcionario a través el soborno. También indica que la evidencia de los mayores abusos se da en la parte occidental del imperio, a partir de la época de Honorio. 
número de hombres como de oficiales, extorsionaban a los provinciales, aterrorizándolos a placer:

Valentiniano III describe el modus operandi de estos discussores ${ }^{37}$ corruptos de la siguiente manera:

Prima sunt venientis exordia, ut proferat et revolvat super diversis numerosisque titulis terribiles iussiones: praetendit minutarum subputationum caligines inexplicabili obscuritate confusas, quae inter homines versutiarum nescios hoc amplius agunt, quo minus intelligi possunt. Securitates expetunt annorum serie et vetustate consumptas, quas servare nescit simplicitas et fiducia nihil debentis.

De este modo, los discussores comenzaban enseñando y desenrollando órdenes terribles sobre numerosos y variados impuestos, sembrando dudas sobre las cuentas presentadas con inexplicable obscuridad, que los hombres, ignorantes de la astucia, no pueden comprender. Se piden recibos destruidos por el paso del tiempo y que los contribuyentes, con la ingenuidad y la confianza de no deber nada, no saben preservar ${ }^{38}$.

Para entender el alcance del fraude cometido hay que tener en cuenta que no se podía efectuar una segunda revisión, una vez recaída carta de pago sobre la primera, pues el recibo, debidamente inscrito en los libros municipales, tenía plena eficacia liberatoria.

Efectivamente, cuando se trataba del pago de los cereales en el caso de la annona militaris, tal y como explica la doctrina ${ }^{39}$ que el recaudador cobraba del contribuyente el importe de su cuota dándole una carta de descargo -apocha, cautio o securitas- que redactaba un annota$t r^{40}$. El contribuyente, después de haber recibido la carta, debía presentarla al director local de archivos y cuentas de la ciudad -tabularius civitatis-, quien la hacía pública registrándola en los libros de la ciudad, apud acta, sobre un libro especial, inscribiéndola después al margen del registro que formaba la matriz de la lista de las contribuciones -polyptici libri-quedando liberado irrevocablemente el deudor mediante esta formalidad ${ }^{41}$.

Cada cuatro meses los tabularii publicaban el estado de los recibos y de las cantidades pendientes de pago - CTh. 12,6,27, $1^{42}$. A veces se cometían irregularidades en el registro de las cartas de liberación o se llegaban a acuerdos fraudulentos con un deudor que hubiera alegado un

37 JONES, The Decline ... cit., p. 174 explica que, en el supuesto contemplado por esta disposición, quienes podían causar más daño eran los canonicarii y los largitiones, por no tener que granjearse el apoyo de la opinión local, al no ser nativos de la provincia y porque solo podían ser juzgados ante la jurisdicción -distante y cara- del Prefecto del Pretorio. Esta es la razón, según este historiador, por la que las asambleas provinciales pedían con frecuencia la abolición de los canonicarii y por la que el gobierno de vez en cuando accedía a sus peticiones, prohibiéndoles tomar parte en la recolección de impuestos o atrasos, limitándolos a supervisar la actividad de los funcionarios provinciales.

${ }^{38}$ MonKs pone el ejemplo, relatado por AMM. MARC. 26,6,17, de Petronio, cuyas reclamaciones de créditos prescritos y títulos caducados -que tenía el arte de hacer revivir- se remontaban al periodo del emperador Aureliano, un siglo atrás.

39 BOUCHARD, op. cit., p. 342 y 451; HuMBERT, op. cit., p. 271 y 284.

${ }^{40}$ En el caso de la annona militaris el recaudador estaría asistido por un medidor, ponderator, encargado de verificar el peso y la cantidad de los productos dados en pago. El recibo debía contener la mención escrita del contribuyente, de la naturaleza y cantidad de los productos, de la causa de la deuda, de la fecha con día, mes y año (CJ 10,22,1,1).

${ }^{41}$ C.Th. 11,1,2 Idem (Constantinus) a. ad Aelianum proconsulem Africae. Possessores cum satisfecerint publicae collationi, cautiones suas ad tabularios publicos deferant, ut eas tabularii sive sexagenarii periculi sui memores suscipiant a collatoribus, ipsas species quae debentur ex horreis suis ad civitates singulas per menses singulos perlaturis, ne illatio tributorum ex solis apochis falsis vel imaginariis cognoscatur. Et cetera. Dat. kal. nov. Treviris Constantino a. IIII et Licinio IIII conss.

${ }^{42}$ C.Th. 12.6.27.1 idem (Honorius et Arcadius) aa. Pompeiano suo salutem. Item a tabulariis quadrimenstruos breves publicari iubemus, ut, si isdem relatae securitates fideliter continent debitum, duplex non teneat exactio. Dat. prid. kal. ian. Mediolano Stilichone et Aureliano conss. (400 d.C.). 
pago ficticio, con la consiguiente emisión de una carta falsa ${ }^{43}$. Por ello se prohibió incluso trasladar a los anotadores en el curso de la misma acusación, para que no pudieran negar su escritura cuando un susceptor o un inspector-discussor- sospechara que el recibo era falso ${ }^{44}$.

Cuando se trataba de la recaudación del tributum soli, pagadero en oro en todas las ciudades, existía un procedimiento similar. El pago del tributo tenía lugar en tres plazos, contra un recibo, apocha, entregado al contribuyente, conforme a las mismas solemnidades, que se enviaba después al archivero contable de la ciudad para ser publicado, registrado y mencionado sobre la matriz de la lista, a través de lo cual la liberación era completa ${ }^{45}$. Tan pronto el cajero local recibía el monto de las cuotas locales lo enviaba a uno de los praepositi thesaurorum situado en una ciudad importante de la provincia. Según el estado de pago comunicado al tabularius central del gobernador, esta persona trasmitía al agente encargado de la ejecución, exactores, el estado de los restos a exigir. El Comes sacrorum largitionum enviaba discussores para controlar las cuentas del recaudador general y del tabularius de la provincia o de la ciudad ${ }^{46}$.

Explica la Novela de Valentiniano que, si los recibos se habían perdido por la causa que fuese, los discussores siempre encontraban una justa ocasión para el despojo, aunque si se habían conservado la situación no era mucho mejor para el contribuyente, a quien le esperan así innumerables calamidades como la cárcel, la horca o las torturas:

\section{Re vera enim aut, quoquomodo pereunt, quasi iusta contingit occasio depraedandi, aut, si extant, redimendum est, ut ferantur accepto. Ita fit, ut apud inprobum rei arbi- trum merito noceat, chartula cum perit, nihil proficiat, non perisse.}

El emperador lamenta que estos casos que afectan a los ciudadanos concluyan, como ocurre con los enemigos, con acuerdos de pago de dinero y no por la justicia de las alegaciones o por la piedad. Por último, observa que, a pesar de que este tipo de persecución nunca aprovecha al fisco, no cesa por ello de ser repetida, como si se hiciera algo eficaz, porque apenas sale un discussor de una provincia, entra otro con nueva autoridad: si el que marchó primero no fue capaz de ser útil al público - concluye- es superfluo que vaya a otro que será igualmente dañino para los provinciales.

Innumerae deinde clades, saeva custodia, suspendiorum crudelitas et universa tormenta, quae interea, laetus et crudelitatis pertinax et egregius quaesitor exspectat. Collega furtorum palatinus hortatur, instat adparitio turbulenta, urget inmitis executio militaris. Indignum facinus, haec de civibus, velut inter hostes pecuniae placitis, non adlegationum iustitia, non miseratione finiri.

A continuación, advierte sobre lo contraproducente que resulta ejercer sobre los ciudadanos una presión fiscal excesiva, pues un contribuyente empobrecido por los impuestos no resulta de utilidad al fisco, que pierde así lo que el recaudador obtiene para su provecho propio ${ }^{47}$.

${ }^{43}$ Clamageran, J., Histoire de l'impot en France, I, Librairie de Guillaumin et Cie., Paris, 1867, p. 67; HuMBERT, op. cit., p. 272. Señala este último que la insinuatio o registro de los recibos pedidos inmediatamente, apud acta y su mención en el libro de matrícula, proporcionaban medios preventivos todavía más eficaces. El recaudador, susceptor, respondía del pago del impuesto, y con él quien lo había designado, el nominator y la curia que lo había elegido; también el gobernador de la provincia debía responder ante los opinatores por el monto de la anona militar atrasada.

${ }^{4}$ Según explica BouchARD, op. cit., p. 342-343, la práctica consistía en que el susceptor hacía trasladar al annotator que había registrado los resguardos de pago, de modo que los nuevos annotatores, al no reconocer su escritura, daban lugar al triunfo de una acusación, con lo que el provincial quedaba obligado a pagar de nuevo.

${ }^{45}$ Cfr. CTh. 11,1,2; 11,25,1; 12,6,18 y CJ, 10,22,3,4.

${ }^{46}$ HuMBerT, op. cit., p. 284-285.

${ }^{47}$ De aquí que MARTíneZ Vela, op. cit., p. 22 afirme que, en el fondo, esta normativa trata de mejorar la situación del Fisco, y no tanto los daños experimentados por los provinciales. 
Tanta vexatio cum nihil umquam fisci utilitatibus prosit, tamen non desinit iterari quasi aliquid efficaciter gestum: vixdum uno e provincia decedente cum novis auctoritatibus alter excurrit. Si utilis publico esse non potuit, qui ante perrexit, superfluum est ire alterum aeque provincialibus obfuturum.

En consecuencia, ordena la remisión de los atrasos hasta el primer año de la indicción que estaba comenzando ${ }^{48}$, prohibiendo expresamente que nadie investigue -discutiat- cosas anteriores al tiempo señalado:

\begin{abstract}
3. Hunc nos, patres conscripti, fomitem perniciosi ardoris extinguimus, nec patimur ulterius ad exhaustorum interitum desaevire. Nobis perit deterior possessor effectus, nobis proficit non gravatus. Venduntur indutiae his, qui non possunt esse solvendo, cum dilationis redemptio publicam magis adtenuet functionem. Amittit sine dubio fiscus, quod commodo suo exactor augmentat. Superiorum igitur, patres conscripti, omnium temporum reliqua tam arcalium, quam utriusque aerarii usque ad incipientem primam indictionem iubemus ad indulgentiam pertinere: nemo prorsus quaelibet usque ad designatum tempus transacta discutiat. Sola est numquam calumnianda securitas, quam aeternitas nostra concedit
\end{abstract}

Para asegurar el cumplimiento de esta norma, dispone que nadie debe aspirar a ser nombrado inspector publicus por decisión judicial; sino que previamente el general Aetius ${ }^{49}$ y el Prefecto del Pretorio debían haber decidido de manera conjunta que el envío del inspector era necesario, determinando, con la participación del Emperador y de su Consilium ${ }^{50}$-aulicis potestatibus-, qué clase de persona debe ser enviada:

\begin{abstract}
Licet hanc humanitatem cunctis ad quietem sciamus posse sufficere, tamen addimus, quo provisio nostra magis possit grata praestari, nemini deinceps licebit ad hoc negotium arbitrio unius iudicis adspirare. Utrum mitti debeat inspector publicus, tractatus ante deliberet sublimis viri parentis patriciique nostri, nec non magnifici viri praefecti praetorio, qui communionis utilitate virtutum suarum magnitudinem nobiscum pervigiles et cogitant et tuentur: cum aulicis potestatibus pro sua moderatione disponant, si iusta necessitas cogit, qualis persona mittatur.
\end{abstract}

Concluye la constitución con una serie de exhortaciones al cumplimiento de la ley, incluyendo la amenaza de un severo castigo contra los discussores que en adelante opriman a las provincias actuando por pura codicia ${ }^{51}$. De igual modo se castigaría el envío de estos funcionarios realizado en contra de lo establecido en esta constitución.

${ }^{48}$ Indica PHARR, C., The Theodosian Code and novels and the Sirmondian constitution, a translation with commentary, glossary and bibliography, Princeton University Press, 1952, p. 516, n. 24 que se referiría del periodo comprendido entre el 1 de septiembre del 447 al 1 de septiembre del 448. La remisión de impuestos acordada en el 450 es una medida que APARICIO PÉREZ, La Hacienda pública....cit., p. 85 enmarca dentro de la situación de debilidad financiera que aquejaba al reinado de Valentiniano III, y que parece entrar en contradicción con otra introducida seis años antes, consistente en la introducción de un nuevo gravamen sobre las ventas -el siliquaticum-.

49 Flavius Aetius fue un importante general y figura central en el reinado de Valentiniano III, quien, en el año 435, le concedió el rango de magnificus vir parens patricusque noster al que se hace alusión en la novela. Acaudilló a los romanos y a sus aliados godos en la célebre batalla de los Campos Cataláunicos, que concluyó con la retirada de Atila (Chron. Cass. 451). Tres años después, el propio Valentiniano, temiendo una usurpación del trono, le asesinó en palacio (Chron. Cass. 454). A partir de aquí se acuñó la frase de que con este hecho el emperador cortó su mano derecha con su mano izquierda. Sobre este personaje, puede consultarse la siguiente bibliografía: JONES, The later...cit., I, p. 197; Martindale, J. R., The Prosopography of the Later Roman Empire, vol. II (A.D. 395-527), Cambridge U.P., Cambridge, 1980, p. 21-29, SEgur, L.P., Histoire du Bas-Empire, I, Paris, 1826, p. 288 y ss.; STEIN, Histoire du Bas Empire, vol. I, De l'Etat Romain a l'Etat byzantin (284-476), Desclée de Brouwer, Paris, 1959, p. 337 y ss.; BURY, History of the later Roman Empire, t. I (from the death of Theodosius I to the death of Justinian), New York, 1958 p. 240 y ss. y TwYMAN, B. L, "Aetius and the Aristocracy", Zeitschrift für Alte Geschichte, Bd. 19, H. 4, 1970, p. 480-503.

${ }^{50}$ PHARR, op. cit., p. 516 n. 28 traduce aulicae potestates como "the Emperor and the imperial consistory".

${ }^{51}$ Nihil impudenter audebit, quem elegit talium virorum examinatus adsensus. Necesse est ab eo integritatis reverentiam custodiri, qui novit tot se custodes habere quot iudices. 5. Aliter pergenti ad provinciam et fortunarum et famae iubemus esse discrimen;revocetur publici timore periculi, quem occulta cupiditas festinare conpellit. Similis condicio 
La doctrina no se pone de acuerdo a la hora de interpretar las causas reales subyacentes a la promulgación de esta novela, lo que quizá se deba a que cada autor se centra en alguna medida en particular de las varias contenidas en la ley:

- $\quad$ Stein $^{52}$ pone el acento en la intención de acabar con la corrupción, con lo que la norma estudiada sería fruto del un sincero intento por parte de Valentiniano III de remediar abusos, aunque resultaría de escaso éxito. También Bouchard ${ }^{53}$ considera que las medidas establecidas en esta novela persiguen acabar con la corrupción.

- Jones $^{54}$ se fija fundamentalmente en la remisión de los atrasos, por lo que a su juicio es probable que la constitución sea una contestación a una petición del senado, pues aunque las alegaciones sobre la maldad de los funcionarios y de las penurias de los possessores escondan cierto punto de verdad, difícilmente justificarían la remisión fiscal acordada, máxime cuando poco tiempo atrás, mediante la Nov. 15 (444 d.C.) prácticamente se proclamaba la bancarrota del tesoro.

- Twyman ${ }^{55}$ se centra en el cambio de competencia acordado para el nombramiento de los discussores. Este autor parte de la hipótesis de que la aristocracia, principalmente la italiana, se alió con la corte imperial en contra de Aetius porque intentaba abolir los privilegios e inmunidades injustos acumulados por la aristocracia; la Nov. 1,3, por tanto, obedecería a la política del propio Aetius, destinada a restringir la autoridad de los funcionarios de la corte, los comites. Lo mismo sucedería probablemente con la Nov. 7.1, del año 440 , en la que se privaba a los comites de ambos tesoros de jurisdicción en los casos en que se sustanciaban quejas contra los senados municipales u otros provinciales, dejando tal jurisdicción en manos del Praefectus Praetorius.

2. La revisión del censo ${ }^{56}$, labor que competía al llamado discussor census o discussor iugerum. El censo, realizado regularmente cada cinco años, estaba basado en la propia declaración del contribuyente - professio censualis- ante el censitor. Las declaraciones eran confirmadas en casos dudosos por el testimonio de algunas personas, incluso por tortura, pero el proceso no iba acompañado de una inspección sobre el terreno. Una vez elaboradas las tablas censuales, eran depositadas por partida doble, en los archivos imperiales de Roma y en la administración municipal.

Si el contribuyente creía haber sido objeto de una estimación injusta, disponía del plazo de un año -a excepción de los menores o los ausentes por causa de la res publica-para efectuar la reclamación, que debía ser resuelta por unos funcionarios distintos de los habituales censitores. Seeck ${ }^{57}$ se refiere a dos etapas: la anterior a Constantino, en la que la función de inspeccionar

manebit officium eius potestatis, quae discussorem mittere cupiens, non fideliter suggesserit adtestatione gestorum formam mittendi, quam statuimus debere servari.

52 STEIN, op. cit., p. 339. Este historiador parte de la idea de que Aetius hizo causa común con los senadores, contribuyendo a debilitar el organismo del Estado, pues de haber tenido la voluntad de hacer triunfar en contra de la aristocracia senatorial las sanas medidas financieras representadas por algunas leyes del emperador habría sido capaz de hacerlo, habida cuenta de los medios de acción que tenía en el plano militar. También COLLOT, op. cit., p. 215 considera que la Nov. Val. 1,3 constituye una medida para acabar con la corrupción descrita en la novela y con las injusticias sociales que esta causa.

${ }^{53}$ BOUCHARD, op. cit., p. 470.

54 JONES, The later...cit., I, p. 365 y III, p. 73, n. 97.

55 TWYMAN, op. cit., p. 488 y ss.

56 Sobre la importancia del censo en el sistema fiscal romano vid. APARICIO PÉREZ, op. cit., p. 312 y ss. y BLANCH Nougués, J.M. Principios básicos de justicia tributaria en la fiscalidad romana, "Revista de Derecho Financiero y Hacienda Pública", vol. 48, n 247, 1998, p. 61 y ss. En relación al procedimiento de elaboración del censo, cfr. HUMBERT., op. cit., p. 197.

${ }^{57}$ SEECK, op. cit., p. 1186. 
el censo correspondía a los examinatores, y la etapa posterior a este emperador, en la que habría de distinguirse entre peraequatores ${ }^{58}$, de rango más elevado, y discussores o inspectores ${ }^{59}$, procedentes de las clases subalternas de la administración de la diócesis. A los primeros se les encomendaría la inspección de toda una provincia, mientras que a los segundos únicamente se les encargaría la inspección de una ciudad.

A la figura del discussor census o iugerum se refieren una serie de constituciones imperiales en las que la tarea de la discussio es tratada como un munus personal ${ }^{60}$, del que, en ocasiones, resultan eximidos determinados colectivos:

a) C.Th. 6,10,1 ${ }^{61}$ (=CJ. 12,7,1). Recoge una constitución de Graciano, Valentiniano y Teodosio dirigida al Prefecto del Pretorio Eutropio, en la que se ordena no molestar a los notarios que cesen en sus funciones -ya sea porque decidan cambiar el trabajo por el descanso, ya porque cesen por causa de edad o por pasar a ostentar otra dignidad-, con labores relativas a los censos ${ }^{62}$, revisiones-discusiones- o igualas-peraequationes- ${ }^{63}$. El quebrantamiento de esta norma es castigado con multa y con el cese del numerarius autor de la ofensa de su puesto.

b) CJ. 11,58,6, en donde se dispone que si los repartidores -peraequatores- o revisores discussores- hubieren actuado con negligencia o favoritismo serán sancionados con la pérdida de sus honores y con la multa de annonas al cuádruplo, sin perjuicio de ser condenados a pagar en el cuádruplo aquello que hubiesen recibido en perjuicio de los provinciales.

c) Una constitución de los emperadores Teodosio y Valentiniano del año 439 prohíbe a los jueces encomendar a los abogados la realización de ninguna inspección -nulla inspectio, iguala -nulla peraequatio-, el cuidado de la construcción de una obra -nulla operis instructio-, examen de cuentas -nulla discussio- ninguna rendición de cuentas -nullum ratiocinium- (Nov. Th. 10, 1,4, posteriormente recogida en CJ. 2,7,6) ${ }^{64}$. En suma, se estaría prohibiendo encomendar a los abogados la imposición de cualquier munus personal, a

${ }^{58}$ Indica APARICIO PÉREZ, op. cit., p. 177, que el peraequator revisaba el trabajo del censitor, aunque su papel principal era el de repartir las tierras estériles o sin dueño entre los demás contribuyentes, con objeto de que fuesen incluidas también en el ciclo de valoración.

59 Señala APARICIO PÉREZ, op. cit., p. 178, que el inspector actuaba cuando en el plazo reglamentario de un año se reclamaba por un particular o por una ciudad contra el reparto realizado.

${ }^{60}$ Cfr. PhARR, op. cit., p. 497, n. 8, quien observa que todas las tareas descritas en la Nov.Th. 10, 6, 4 constituyen servicios públicos obligatorios no remunerados.

${ }^{61}$ C.Th. 6,10,1 -Imppp. Gratianus, Valentinianus et Theodosius aaa. Eutropio praefecto praetorio.Praecipua est nostrae pietatis intentio circa notariorum nomen, atque ideo, si umquam huius ordinis viri laborem quiete mutaverint vel senectute posuerint seu cum alia dignitate post hanc qualibet usi sunt, non omittant prioris vocabulum militiae, sed compendium sequentis honoris adsumant. Et si quis ex officio vel praecipue sublimitatis tuae temerarius ad census discussiones peraequationes, aliam denique ullam rem inquietator extiterit, officium suum norit vel levis culpae offensione detecta gravis multae discrimine fatigandum et numerariorum corpus extincto iniuriae auctore minuendum. Dat. xvii kal. iul. Thessalonica Gratiano v et Theodosio i aa. conss. (380 d.C.).

${ }^{62}$ Se señala que, dada la importancia del censo para la fiscalidad romana, el término census acaba apareciendo en las fuentes como sinónimo de contribución pública (BLANCH NOUGUÉS, cit., p. 65; Clamageran, Histoire ...cit., p. 7).

${ }^{63} \mathrm{Y}$ así indica BARTOLO DE SAXOFERRATO (Fehi, t. V, col. 241) que a los notarios que abandonen su oficio por la vejez o por pasar a mayor dignidad no pierden por esto su nombre de notarios, sino que mantienen la dignidad y privilegios propios de estos, pero no pueden ser discussores, ni peraequatores o tener dignidades similares con administración.

${ }^{64}$ CJ. 2.7.6. Imperatores Theodosius, Valentinianus. Sancimus, ut advocatis, qui apud tuam magnificentiam causas acturi sunt, a nullo iudice, nec ab ipsa eminentissima praefectura, sollicitudo ulla penitus iniungatur: sed nec advocatis provinciarum vel spectabilium iudicum quisquis existimet aliquid iniungendum. Nulla igitur togatis inspectio, nulla ingeratur peraequatio, nulla operis instructio, nulla discussio, nullum ratiocinium imponatur, nullum denique aliud eis mandetur praeter arbitrium in eodem dumtaxat loco ubi advocationis exercetur officium: quinquaginta librarum auri poena officio feriendo, quod legis istius regulas temerare temptaverit. THEODOS. ET VALENTIN. AA. AD FLORENTIUM p. *A 439 D. XIII K. maio CONSTANTINOPOLI THEODOSIO A. XVII ET FES TO CONSS. 
excepción de la necesidad de aconsejar, actuar como árbitros y juzgar ${ }^{65}$. Explica Bluhme ${ }^{66}$ que esta ley fue aprobada con el propósito de retener a los abogados en los tribunales locales, pues por causa de las numerosas cargas impuestas, así como por el deseo de ejercer ante los tribunales más altos del imperio, muchos se marchaban a Constantinopla.

d) CJ. 10,30,3. Este fragmento de la compilación justinianea recoge una constitución que estos mismos emperadores dirigen a Apolonio, Prefecto del Pretorio en el 442 d.C. En ella ordenan que en cada provincia o ciudad se encomiende la revisión de las yugadas discusionis iugorum- a los que pertenezcan al rango de hasta la comitiva consistorial, a quienes están en el servicio imperial pero no se encuentran ejerciendo y a los abogados del foro de la provincia - a quienes, según se ha visto, tan solo tres años antes había eximido de este tipo de obligaciones ${ }^{67}$. Por ello afirma Bartolo de Sassoferrato que del munus de la discussio o de la estimación del patrimonio nadie está excusado ${ }^{68}$.

Poco después la Nov. Val. 32,7 permite que los abogados del foro de la provincia puedan marchar a Constantinopla si dejan sus funciones locales desarrolladas por sustitutos, siempre y cuando hubiera suficientes abogados en la provincia (al menos cuatro).

3. El examen de las obras públicas y de las cuentas sobre los fondos destinados a su ejecución. Esta función, que encaja más bien con las de intervención fiscal ${ }^{69}$, es la que aparece reflejada en el epítome de la constitución griega que se recoge en CJ. 10,30,4. El problema aparecía, fundamentalmente, cuando las obras habían sido sufragadas con fondos de las ciudades o de manera voluntaria por los particulares. Efectivamente, hay que tener en cuenta que la financiación privada (en ocasiones forzosa) jugaba un importante papel en el desarrollo de las obras públicas bajoimperiales ${ }^{70}$.

Del tema se ocupa por primera vez la Nov. 22 de Teodosio II (De bonis decurionum et de naturalibus filiis eorum in curiam mittendis heredibusque scribendis) dejando constancia de los abusos que en este terreno cometían los discussores. La constitución, fechada en el año 442, se dirige a Apolonio, Prefecto del Pretorio, que, en su informe al emperador se había quejado de haber sido víctima de una situación injusta. Resultaba frecuente, según se deduce de las palabras

${ }^{65}$ Cfr. Baldo DEgli UBALdi, en FeHI, op. cit., t. IV, col. 384 (ad CJ. 2,7,6): Advocatis nullum munus personale debet iniungi, nisi necessitas consulendi, arbitrandi \&iudicandi.

${ }^{66}$ Bluhme, F. H., The Annotated Justinian Code, Book II, Title VII, n. 4 (disponible en http://www.uwyo.edu/lawlib/ blume-justinian/ajc-edition-2/books/book2/book\%202-7rev.pdf)

${ }^{67}$ CJ. 10,30,3. Imperatores Theodosius, Valentinianus. Per singulas provincias vel civitates honoratis usque ad comitivam consistorianam nec non etiam militantibus et suis obsequiis non adhaerentibus, advocatis quin etiam fori provincialis mandari discussionis iugorum sollicitudinem decernimus. THEODOS. ET VALENTIN. AA. APOLLONIO p. A 442 D. V K. IAN. EUDOXIO ET DIOSCORO CONSS. Para conciliar esta disposición con la anterior BLUHME, op. cit., 10,30,4 (http://www.uwyo.edu/lawlib/blume-justinian/ajc-edition-2/books/book10/ book10-30rev.pdf) propone interpretarla en el sentido de que los abogados del foro de la provincia podían ser nombrados auditores con su consentimiento, pero no podrían ser obligados a aceptar el nombramiento. BRUNNEMAN, J., Commentarius in codicem justinianeum, Lipsiae, 1699, t. II, p. 1195, en su momento hatía tratado de salvar la contradicción observando que mientras que la Nov. Th. 10, 1,4 está contemplando es una discussio operis, la constitución recogida en CJ. 10.30,3 se refiere a la discussio iugerum. Una tercera posibilidad sería, evidentemente, considerar que se produjo un cambio de criterio en la legislación imperial.

${ }^{68}$ BARtolo a SAXo Ferrato, en FeHI, op. cit., t. V, col. 46 (ad CJ. 10,30,3) Ab onere discutiendi, \& aestimandi patrimonia nullus excusatur, nec etiam miles, nec militans.

${ }^{69}$ Advierte RODRÍGUEZ LÓPEZ, op. cit., p. 436 de los peligros que conlleva cualquier traspolación a la hora de usar la terminología propia de la ciencia financiera actual a los actos fiscales realizados en Roma.

${ }^{70}$ Cfr. Malavé Osuna, B., Régimen jurídico financiero de las obras públicas en el Derecho romano tardío: los modelos privado y público de financiación, Dykinson, Madrid, 2007, p. 65 y ss. Las razones que conducían, a su juicio, a dar a la financiación voluntaria de los particulares ese lugar preeminente serían la bonanza económica experimentada por el Imperio ya desde los últimos años de la República y el sentido patriótico o religioso de algunos ciudadanos, aunque, en realidad, la fama y la popularidad serviría de estímulo las más de las veces. 
del emperador, que ciertas personas que no eran decuriones por nacimiento realizasen espontáneamente importantes donaciones a su municipio o que contribuyesen a su exaltación embelleciendo algunos edificios.

Aunque el emperador entiende que esta conducta merece las mayores alabanzas, sin embargo, reconoce que a algunos les ha reportado sufrir las cargas de los decuriones -sin que estas les correspondieran- o incómodas inspecciones. Aduciendo que es indignante que a una persona se le exija rendir cuentas de su generosidad, cuando no se le habría hecho rendir cuentas de su lujo, Teodosio prohíbe que en estos casos se realizar cualquier tipo de investigación ${ }^{71}$.

Menos de medio siglo después, el emperador Zenón dicta una nueva constitución sobre el tema, dirigida a Arcadio, Prefecto del Pretorio y fechada en el año 485 ó 486:

\begin{abstract}
CJ. 8,13(12) pr. Imperator Zeno. Iubemus provinciarum quidem rectores et singulae dioeceseos viros spectabiles iudices, id est praefectum Augustalem et comitem Orientis et utrosque proconsules et vicarios una cum suis apparitoribus pro tenore generalium magnificae tuae sedis dispositionum discutiendis publicis operibus vel aquae ductibus, qui ex civilibus reditibus vel a quolibet spontanea munificentia facti sunt vel fuerint, modis omnibus abstinere, nec aliquid quolibet modo quolibet tempore in discutiendo civiles reditus vel facta opera vel quae fieri adsolent, unam siliquam sibi ex singulis erogandis solidis vindicando aut quodcumque lucrum captando, cum huiusmodi rebus habere commune, utpote patribus civitatium et curae eorum deputatis.
\end{abstract}

En esta constitución el emperador ordena que los gobernadores provinciales, el Praefecto Augusti, el Comes de Oriente, los Procóncules, Vicarios y sus alguaciles, se abstengan de examinar las obras de las ciudades cuando estas hayan sido sufragadas mediante fondos municipales o por la espontánea liberalidad de los particulares, absteniéndose de cobrar una siliqua por sólido gastado, como se venía haciendo hasta la fecha ${ }^{72}$, pues tal tarea estaba encomendada a los padres de las ciudades -patribus civitatium- es decir, a los jueces y magistrados ${ }^{73}$.

A continuación, Zenón recuerda que quien hubiese prometido que haría por su propia generosidad una obra en favor de la ciudad está obligado a realizarla. El texto constituye un claro ejemplo de la voluntad unilateral como fuente de obligaciones, la pollicitatio $^{74}$. De lo que exime el emperador en tales casos, en la línea establecida por Teodosio II, es de la necesidad de cualquier procedimiento de inspección; lo que priva a los discussores de la posibilidad de embolsarse $1 / 24$ de lo gastado en las obras.

${ }^{71}$ Nov. Th. 22,2. Quapropter ipsis civitatibus potissimum consulentes, quibus suorum civium benevolentiam nolumus interclusam, huius aeternae legis saluberrima latione decernimus, ut, si quis sua sponte nullique eiusmodi oneri subditus in qualibet civitate per se alteriusve personam quodcumque munus ediderit vel honorem gesserit, nullum ex voluntaria largitate vel praeiudicium sui status incurrat vel discussionis ratiociniis obligetur.

${ }^{72}$ La siliqua era una moneda de plata equivalente a una vigésima cuarta parte del solido de oro, con un peso de 3,4 gramos (cfr. APARICIO Perez, La Hacienda Pública... cit., p. 519).

73 Cfr. FeHI, Corpus Glossatorum Juris Civilis, t. IV, Lugduni, 1627 col. 2093, Gl. b) Patribus civitatum. i.b/ defensoribus, scilicet supradictis commemoratis personis, sc. Iudicibus \& magistratibus. b/ Hinc colligunt puniri poena parricidii qui officialem interfecerit adde huic Gl. aliam, quae in Novella de defensoribus 15.c.

${ }^{74}$ Sobre la pollicitatio vid. IGLESIAS REDONDO, J., "La pollicitatio", Derecho romano de obligaciones en homenaje al profesor José Luis Murga Gener, coord. Paricio, ed. Centro de Estudios Ramón Areces, Madrid, 1994, p. 495 y ss. Distingue el autor en el Derecho clásico entre la pollicitatio ob honorem -aquella que tiene como contraprestación la elección para un cargo público, de eficacia obligatoria- y la pollicitatio non ob honorem -desprovista de fuerza obligatoria salvo que haya comenzado ya la obra prometida, y que por carecer de contraprestación, debería ser considerada como donación, sujeta por tanto a la exceptio legis Cincia-. En el Derecho justinianeo habría que distinguir entre pollicitatio ob iustam causam, entendida como la promesas efectuada en favor de la civitas con ocasión de calamidades públicas o para enriquecerla con obras públicas, y la pollicitatio sine causa, más difícil de encontrar en la práctica, y cuyo cumplimiento no sería exigible salvo que la obra se hubiera iniciado. 
La constitución de Justiniano recogida en CJ. 1,4,26,pr. encomienda el control de las obras de los gastos públicos a una comisión, constituida por el obispo y tres personas de buena reputación de la ciudad, que posteriormente la Nov. 128,16 elevaría a cinco. Se ha observado que esta medida refleja el deseo del emperador de evitar las injerencias del Prefecto del Pretorio en la administración local ${ }^{75}$.

En todo caso, quedaba a salvo el derecho del propio emperador, si así lo deseaba, de enviar inspectores para supervisar las cuentas o medir la obra ${ }^{76}$, tanto si la obra pública fue sufragada con dinero enviado a tal fin por el erario público como si procedía de cantidades dejadas a las ciudades, mediante una suma global o un pago periódico:

\begin{abstract}
Nam ipse Princeps, sive ex aerario pecunias miserit ad moenium alteriusve operis constructionem, sive ab alio relictas civitatibus pecunias, vel semel, vel in perpetuum invenerit, cum ipse placuerit, mittit discussorem, qui opus admetiatur, et rationes putet exacte, et ad se referat ${ }^{77}$.
\end{abstract}

Las medidas para proteger a los administrados y a las ciudades frente a interventores que no hayan sido enviados directamente por el emperador continúan en las Novelas de Justiniano. Efectivamente, en la Nov. 17,4 (535 d.C) aparece la advertencia de que no se atenderá a nadie que se presente a comprobar la efectiva ejecución de obras públicas o de la correcta auditoría de las cuentas municipales más que si se presenta pragmática disposición escrita del emperador; se establece, además, la precaución adicional de que no se hará nada hasta haber comunicado esta circunstancia al emperador y haberse recibido de este un segundo mandato confirmatorio.

En una constitución del año siguiente (536), que nos trasmite la Nov. 30, 8, se contiene una previsión similar $^{78}$ : si el emperador considera necesaria una inspección sobre las obras o cuentas de las ciudades, dirigirá una pragmática al encargado de la administración.

Más adelante, en la Nov. 128,18 (545 d.C.), Justiniano prohibirá nuevamente el envío de inspectores por parte del Prefecto del Pretorio, reiterando la competencia exclusiva del propio emperador, que elegirá a varón de buena fama y revestido de dignidad - virum opiniones bonae et dignitate ornatur- y al que dará mandato escrito en el que constará el nombre y dignidad del elegido y las causas y el tiempo al que se refieren las cuentas encomendadas.

4. Recuperación de los terrenos entregados ilegalmente en la concesión de terrae laetica $^{79}$. Efectivamente, el CTh. 13,11,10 ${ }^{80}$ recoge una constitución del año 399 en la que los emperadores Arcadio y Honorio envían un inspector idoneus con esta finalidad. La

75 BURY, op. cit., t. II, p. 351.

76 Bas. 56,10,2, "De collatione aeris et de retractationes", cuyo epítome se recoge en CJ. 10,30,4-9.

77 Bas. 56,10 "De collatione aeris et de retractationibus", cuyo epítome se recoge en CJ. 10,30,4-9. Texto en latín tomado de HeimBaCH, C.G.E., Basilicorum libri LX, t. V, Lipsiae 1850 V, p. 169.

${ }^{78}$ Nov. 30,8 ...Si enim quandam perspexerit quidem inspectionem fieri, hanc nos divino pragmatico utentes typo ad eum qui administrationem hanc habet et tuae de hoc sedi communicantes causam disponimus, ut nulli tales pecuniae collectiones ingressibiles et incursibiles facile fiant. Qui autem administrationem habet maxime quidem per se omnia prohibebit; si vero aliquid etiam vehementius indiguerit, nuntiabit et ad tuam celsitudinem et ad gloriosissimum praepositum et ad alios famosissimos nostros iudices, quibus aliqua est ad causam participatio, et ad nos ipsos, nosque ipsum quod agendum est explanabimus.

${ }^{79}$ Sobre las terrae laeticae vid. PAPA, G., "Multae gentes... quibus terrae laeticae administrandae sunt. A proposito di CTh. 13.11.10", SDHI, 82, 2016, p. 177 y ss; JONES, op. cit., t. II, p. 620 y SzIDAT, J., "Terrae Laeticae (Cod. Theod. 13,11,10)", Historische Interpretationen. Gerold Waser zum 75. Geburtstag, Weinmann-Walser ed., Franz Steiner Verlag, Stuttgart, 1995, p. 151 y ss.

${ }^{80} \mathrm{CTh} .13,11,10$. Idem aa. Messalae praefecto praetorio. Quoniam ex multis gentibus sequentes Romanam felicitatem se ad nostrum imperium contulerunt, quibus terrae laeticae administrandae sunt, nullus ex his agris aliquid nisi ex nostra adnotatione mereatur. Et quoniam aliquanti aut amplius quam meruerant occuparunt aut colludio principalium vel defensorum vel subrepticiis rescriptis maiorem, quam ratio poscebat, terrarum modum sunt consecuti, inspector idoneus dirigatur, qui ea revocet, quae aut male sunt tradita aut improbe ab aliquibus occupata. Dat. non. april. Mediolano Theodoro v. c. cons. (399 d.C.). 
expresión terrae laeticae se refiere a las tierras reservadas por el gobierno para los bárbaros que querían asentarse dentro de las fronteras del imperio. Se ha propuesto que se trataría de tierras vacantes por haber sido abandonadas por sus antiguos poseedores, obligados a huir ante el invasor, de modo que volvían a ser incluidas dentro del ager publicus, teniendo entonces el gobierno el derecho de disponer de ellas para asegurar la defensa del territorio ${ }^{81}$.

Como explica $\mathrm{Papa}^{82}$, la constitución de Honorio y Arcadio trata de poner fin a la corruptela según la cual algunas personas, a veces con la colusión de los principales o de los defensores civitatium, a veces por medio de ocupaciones abusivas, obtenían más tierras de las que le correspondían. La reacción imperial se plasma en el envío de un inspector idoneus con la tarea de revocar las entregas mal hechas o las ocupaciones efectuadas.

5. Fijación de los precios del mercado, tarea que en ocasiones se encomendaba a discussores nombrados por los gobernadores provinciales. Así, los emperadores Arcadio y Honorio dispusieron en el año 396 que ninguna persona que no fuera judía pudiera fijar los precios cuando éstos ofrecieran sus mercancías a la venta; por esta razón los gobernadores provinciales no podrían permitir que nadie ajeno a dicha religión fuese nombrado discussor o moderator para los judíos, castigándolo con suplicio, como usurpador de derechos ajenos (CTh.16,8,10 = CJ. 1,9,9,pr. ${ }^{83}$ ).

6. El conocimiento de determinadas causas en materia fiscal. Critica acertadamente Pergami ${ }^{84}$ a Godofredo y a Seeck cuando observa que ninguno de los dos estudiosos se ha ocupado de la actividad jurisdiccional del discussor. El autor concluye que es posible diferenciar dos momentos en la actividad de este funcionario: uno de naturaleza meramente administrativa, dirigido a la investigación del impuesto (status discussoris) y el de naturaleza jurisdiccional, destinado a decidir sobre la contestación que se hubiera podido formular contra la investigación ${ }^{85}$.

Esta teoría permite salvar la aparente antinomia que se produce en materia de apelación ${ }^{86}$ entre dos fragmentos del Código Teodosiano, en los que se recogen sendas disposiciones fechadas el 14 de febrero del año 374, de los emperadores Valentiniano, Valente y Graciano dirigidas a Eupraxius, Praefectus $\mathrm{Urbi}^{87}$ :

${ }^{81}$ LEOTARD, E., Essai sur la condition des barbares établis dans l'empire romain au quatriéme siécle, Paris, 1873, p. 129, seguido por PAPA, op. cit., p. 178, n.1.

82 PAPA, op. cit., p. 181.

${ }^{83}$ C.Th., 16,8,10 (= CJ. 1,9,9) Impp. Arcadius et Honorius aa. ad iudaeos. Nemo exterus religionis iudaeorum iudaeis pretia statuet, cum venalia proponentur: iustum est enim sua cuique committere. Itaque rectores provinciae vobis nullum discussorem aut moderatorem esse concedent. Quod si quis sumere sibi curam praeter vos proceresque vestros audeat, tum velut aliena adpetentem supplicio coherceri festinent. Dat. III kal. mart. Constantinopoli Arcadio IIII et Honorio III aa. conss. (396 d.C.).

${ }^{84}$ Pergami, op. cit., p. 360.

${ }^{85}$ En igual sentido Agudo RuIZ, A., "La apelación fiscal en la legislación imperial del Codex Theodosianus", en Estudios de Derecho fiscal romano, Dykinson, Madrid, 2016, p. 217.

${ }^{86}$ Indica AGUDO RUIZ, op. cit, p. 174, que la mayor preocupación de la cancillería imperial, a tenor del número de disposiciones legislativas, es la relativa a la inútil prolongación de los juicios de naturaleza fiscal a través de la apelación, lo que obligará a prohibir la apelación fiscal en determinadas circunstancias para evitar que el efecto suspensivo produzca consecuencias lesivas para la administración fiscal. Los problemas financieros -añade- que ya habían influido en la legislación de Constancio y Constante, induciéndoles a limitar la apelación contra las sentencias por las deudas fiscales o relativas a la res privata, al menos cuando tuviesen finalidades manifiestamente infundadas o dilatorias, se dejan sentir en la legislación de Valentiniano I, Valente y Graciano con mayor rigor (op. cit., p. 205).

${ }^{87}$ Señala AGUDo RuIZ, op. cit., p. 213, que se trata de una única constitución dividida por los compiladores en tres fragmentos. El tercero correspondería a C. Th. 11,29,5, sin interés para el tema que nos ocupa. 
- En el primero, CTh. 11,36,21, ordenan los emperadores a los inspectores del fisco no permitir ninguna apelación de los deudores manifiestos ${ }^{88}$. Según observa Godofredo, a este tipo de deudores se les denegaba incluso el asilo o refugio público en una Iglesia, tal y como pone de manifiesto una constitución de los emperadores Teodosio I, Honorio y Arcadio del año 392, recogida en C.Th. 9,45,189, en la que obligaban a los obispos a expulsar a tales deudores de la Iglesia si no querían que se les exigiera a ellos mismos el pago de la deuda por haber dado cobijo al deudor.

- En la segunda, recogida en C.Th. 11,30,36, los mismos emperadores dicen que si existe algún punto poco claro y por causa justificada resulta imposible resolver un asunto inmediatamente, si el deudor del fisco se opone a la decisión del investigador fiscal, se debe evitar todo retraso, correspondiendo al Praefectus Urbi o al vicario - a aquel de los dos que esté más cerca ${ }^{90}$-, resolver el punto ambiguo o incierto suscitado ${ }^{91}$.

De este modo, se considera que la actividad del discussor contemplada en este segundo fragmento, a diferencia de la del primero, no es de naturaleza jurisdiccional, sino administrativa. A la misma conclusión lleva el empleo del término discussiones statum en CTh. 11,30,36 en lugar del sententiam discussoris que aparece en otros textos, como CTh. 11,30,45, en el que se contempla una actividad jurisdiccional del discussor.

En CTh. 11,36,29 (=CJ. 7,65,7) se recoge una constitución de Valentiniano, Valente y Teodosio dada en Milán en el 385 y dirigida al Comes rerum privatarum Pelagio, en la que se establece la prohibición de apelar sentencias interlocutorias del revisor de cuentas-discussor- o del contador -rationalis- debiendo esperar, por tanto, a la sentencia final para poder formular apelación ${ }^{92}$.

Los mismos emperadores establecen la competencia del Comes rerum privatarum para conocer de las apelaciones contra las sentencias del discussor o del rationalis, admitiendo la

${ }^{88}$ C.Th. 11.36.21 [=Brev. Alar. 11.11.4] Iidem aaa. ad Eupraxium pf. U. Post alia: a discussoribus observari iubemus, ut manifesti debitores provocationis suffragio minime subleventur etc. p. XVI. kal. mart. Gratiano a. III. et Equitio coss. Interpretatio. Omnes, qui huius modi negotia discutiunt, hoc specialiter observare debere, ut manifesti debitores appellationis suffragio non utantur, nec evidens debitum ulla possint appellationis dilatione suspendere.

${ }^{89}$ C.Th. 9,45,1. Imppp. Theodosius, Arcadius et Honorius aaa. Romulo comiti sacrarum largitionum. Publicos debitores, si confugiendum ad ecclesias crediderint, aut ilico extrahi de latebris oportebit aut pro his ipsos, qui eos occultare probantur, episcopos exigi. Sciat igitur praecellens auctoritas tua neminem debitorum posthac a clericis defendendum aut per eos eius, quem defendendum esse crediderint, debitum esse solvendum. Dat. XV kal. nov. Constantinopoli Arcadio a. II et Rufino conss. (18 de octubre de 392). Cfr. GOTHOFREDI, Codex Theodosianus, t. IV, cit., p. 327. STEIN, op. cit., p. 195, inscribe la prohibición de Teodosio I de dar asilo a los deudores fiscales en las iglesias en el marco de las medidas para acentuar la presión fiscal como modo de compensar el incremento del déficit provocado por la política de Teodosio I, que había entrañado un considerable aumento de los gastos del Estado. Al propio tiempo, la capacidad contributiva del Ilírico se había visto mermada por las devastaciones previas al acuerdo de paz.

90 Sobre la cuestión de si la competencia del Vicario era subsidiaria o concurrente con la del Praefectus Urbi, vid. AGUDO RUIZ, op. cit., p. 215. El autor considera la alternatividad del texto solo aparente, por lo que solo si el Preafectus prestara su consentimiento, podría ser sustituido por el vicario o por otro juez.

${ }^{91}$ CTh. 11.30.36. Imppp. Valentinianus, Valens et Gratianus aaa. ad Eupraxium praefectum Urbi. Post alia: cum ex causis iustis aliquid, quo minus iudicari statim possit, repperietur incertum ac debitor adversus discussoris statum coeperit reluctari, dilatione postposita super eo, quod exorietur ambiguum, vel sublimitas tua vel vicarius, prout quisque vestrum proximus erit, adhibeat examen. Proposita XVI kal. mart. Gratiano a. III et Equitio conss. (374). Entiende PERGAMI, op. cit., p. 361 que, mientras la contestación del status discussiones normalmente tenían lugar ante el propio discussor, que decidía mediante sentencia, le disposición comentada recoge un caso particular, en el que la contestación era elevada en recurso meramente administrativo ante el órgano superior cuando por justa causa no era posible decidir inmediatamente.

92 Cfr. Agudo Ruiz, op. cit, p. 224. 
posibilidad de delegar en el gobernador provincial si se trata de una cuestión de poca importancia o de una región muy alejada (CTh. 11, 30, 45, pr. = CJ. 7,62,26) ${ }^{93}$.

\section{DERECHOS Y OBLIGACIONES}

La principal obligación de los discussores sería, evidentemente, la de desempeñar la función para la que han sido nombrados sin realizar lucro ni de un solo óbolo ${ }^{94}$-ne unius quidem oboli lucrum facere- respetando tanto los derechos del erario como de los contribuyentes, según se expresa en CJ. 10, 30, 4, 3. ${ }^{95}$

Por lo que se refiere a sus deberes frente al erario público, la obligación fundamental sería la de no defraudarle.

Como principales obligaciones de los discussores frente a los contribuyentes, podrían indicarse:

- la de realizar la revisión de las cuentas con justicia, pudiendo demostrar la verdad del hecho (CTh. 11, 26, 1; CJ. 10, 30, 1)

- la de no cobrar por la emisión de los recibos de pago (CTh. 12, 6, 18).

- la de no volver a pedir por segunda vez los documentos justificativos del pago (Nov. Val. 1, 3; CTh. 11, 26, 2; CJ. 10, 30, 2).

Las consecuencias derivadas de la contravención de todas estas obligaciones las analizaremos en el apartado correspondiente al régimen sancionador.

Entre los derechos que les corresponden, cabe citar los siguientes:

${ }^{93}$ CTh. 11, 30, 45. Idem AAA. et Arcad. A. ad Pelagium com. rer. privat. Post alia: Cum post sententiam discussoris vel rationalis fuerit provocatum, ad sinceritatem tuam negotium transferatur, ut, si mediocritas negotii aut longinquitas regionis ad iudicium tuum litigatores venire non patitur, iudici provinciae, quem ipse probaveris, negotium deleges. La doctrina señala que se trata de un fragmento que corresponde a la misma constitución que aparece en CTh. 11,36,29, antes comentada, y que los compiladores separaron.

94 Para Chantraine, P., Dictionnaire Étymologique de la Langue Grecque. Historie des Mots, I, Paris, 1968, p. 771, el

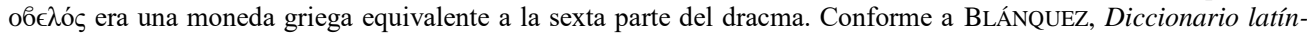
español, t. I, Sopena, Madrid, 2002, p. 39, en el Imperio se introdujo el sistema monetario griego, debiéndose distinguir: la mina (360 gr.), equivalente a 100 dracmas (3,60gr.), cada uno de los cuales se dividía en 3 scrupulus (1,20 gr.); estos a su vez en 2 obolus (0'60 gr.) y cada uno de ellos en a 3 siliquas (0'20 gr.). Du CANGE, Glossarium mediae

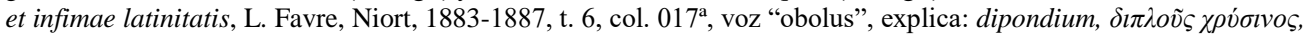

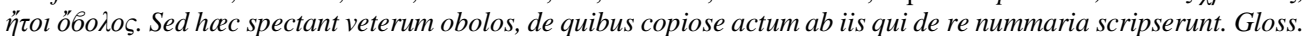
Biblica MSS. anonymi ex Bibl. Reg.: Obolus, dimidius scrupulus. Item, Obolus dicitur medalia, scilicet medietas nummi». Precisamente con este apelativo de dupondios "tan frívolo como ridículo", según Justiniano, se designaba a los estudiantes de primer año de Derecho, en el sentido de algo de poco valor, según se refiere en la constitución Omnem reipublicae $\$ 2$, en la que Justiniano ordena, para el futuro, que dichos estudiantes sean apellidados "Nuevos Justinianos", en atención a las Instituciones que llevan su nombre y que se habrían de estudiar durante el primer curso. El obolus puede significar precio módico o insignificante (cfr. BLÁZQUEZ, op. cit., t. II, p. 1044). En castellano actual la palabra "óbolo" también puede ser sinónimo de limosna o pequeña cantidad con la que se contribuye a un fin determinado. En cualquier caso, la constitución imperial emplea el término óbolo como algo de escaso valor, y el sentido de la norma es claro: el discussor no podrá apropiarse de ninguna cantidad, por insignificante que sea, en fraude del fisco o de los contribuyentes: nullos vero praesidum mittat discussorem, sed referat ad imperatorem, ut ab hoc earum rerum discussor mittatur, que ne unius quidem oboli lucrum facere, sed tam publicis rationibus quam collatoribus ius suum conservare debeat.

${ }^{95}$ CJ. 10, 30, 4, 3 Nullus vero praesidum mittat discussorem, sed referat ad imperatorem, ut ab hoc earum rerum discussor mittatur, qui ne unius quidem oboli lucrum facere, sed tam publicis rationibus quam collatoribus ius suum conservare debeat. 
- Ser indemnizados por los gastos en los que hayan podido incurrir en el ejercicio de sus funciones, (CJ. 10, 30, 4, 1) ${ }^{96}$. Los discussores eran reintegrados de estos gastos por el Estado, no por los contribuyentes ${ }^{97}$.

- Recibir seis sueldos por cada libra de dinero debido por los contribuyentes y que como consecuencia de su actuación hubiere sido ingresada en el erario (CJ. 10, 30, 4, 4) ${ }^{98}$. Procopio hace referencia a que tenían derecho a una doceava parte de lo ingresado, lo cual confirma en la práctica lo dispuesto en la constitución del Codex de Justiniano ${ }^{99}$.

\section{Medidas CAUTElares Para PREVENIR ABUSOS O SUPLANTA- CIONES}

Quizá en correspondencia con la imagen negativa que, según se indicó, suelen reflejar las fuentes literarias que mencionan a los discussores, la mayor parte de la legislación imperial relacionada con estos funcionarios se dirige casi siempre a establecer límites a su actuación y a imponer un riguroso régimen sancionador. Entre las medidas preventivas de los abusos cabe citar las siguientes:

1) Establecimiento de la competencia exclusiva de determinados funcionarios o incluso del propio emperador para su nombramiento. De este modo, como ya se indicó, Valentiniano III dispuso en el año 438 que únicamente el Praefectus Pretorio, previa deliberación con el general Aetius podían enviar discussores a provincias, con la finalidad de evitar los abusos descritos en la constitución. Se prohibía expresamente que los jueces decidieran el envío de un inspector publicus (Nov. Val. 1, 3, 4).

En la época de Justiniano, los discussores debían ser nombrados directamente por el emperador, para intervenir las cuentas correspondientes a las obras públicas, en virtud de un mandato especial ${ }^{100}$. La constitución justifica esta competencia exclusiva del príncipe por la necesidad de encomendar la inspección de este tipo de negocios a un varón íntegro, que realice su tarea en beneficio de las ciudades y no en provecho propio ${ }^{101}$.

Carecían, por tanto, de la facultad de nombrar discussor tanto los prefectos como los jueces (CJ. 10,30,4, pr.) Ni siquiera procedía su nombramiento por parte del gobernador provincial, estableciéndose graves multas para quien contraviniese esta disposición (CJ. 10,30,4, 7). Si el infractor era el presidente de la provincia, sería multado con veinte libras de oro y con el más

${ }^{96}$ CJ. 10,30,4,1. Pollicetur etiam sumtus discussoribus constitutio, ut sine damno discussionem tractare possint.

${ }^{97}$ Gothofredi, D. Corpus Juris Civilis Romani, t. IV, Neapoli, 1830, p. 919, n. 5.

${ }^{98}$ CJ. 10,30,4,4. Quodsi discussor inventas apud aliquos publicas pecunias exegerit, et in sacrum ornamentum intulerit, licet ei in singulis libris sex solidos pro ministerio suo retinere (...).

99 Procopio, Historia Secreta, 24,1,2. Hay que tener en cuenta que un sólido equivalía a 1/72 libras (aproximadamente 327 gr.), según indica APARICIO PÉREZ, op. cit., p. 520. Por tanto, seis sueldos equivaldrían a 1/12 de libra, por lo que ambas fuentes vienen a coincidir.

${ }^{100}$ Explica JONES, op. cit., t. II, p. 405, que con el curso del tiempo se incrementa la centralización, existiendo una tendencia creciente por parte de las más altas autoridades de interferir directamente en las esferas de sus subordinados. De este modo, el Gobernador provincial, en vez de dejar que los oficiales de cada curia recaudaran sus impuestos, usaba sus oficiales para tratar con los contribuyentes recalcitrantes. Por otra parte, la auditoría de las cuentas locales por los discussores o logotetas enviados por el prefecto del pretorio se hicieron cada vez más comunes en los siglos V y VI. Cuando estos oficiales, como los palatini y canonicarii abusaron de su poder en su propio beneficio, el único remedio que Justiniano pudo arbitrar fue ordenar que debían ser enviados por orden personal suya. Y cuando descubrió que tales ordenes eran igualmente enviadas sin su conocimiento, autorizó a las autoridades de las ciudades a enviar a Constantinopla y verificar las credenciales del auditor.

${ }^{101}$ CJ. 10,30,4, 7 in fine: Soli enim principi licet, in eiusmodi causis inspectionem mandare viro integro, qui fideliter et pro utilitate civitatum haec perquirat, nec quidquam propterea auferat. 
severo castigo del príncipe. Si se trataba de un oficial, procedería pena corporal, además de multa de quince libras de oro.

También correspondía en exclusiva al emperador el envío a los campos de revisores, contadores o liquidadores para el examen de las cuentas públicas. Justiniano priva expresamente de esta facultad a los presidentes de las provincias (CJ. 1,4,26,1) ${ }^{102}$.

2) En el caso de la inspección de las cuentas de las obras públicas, el obispo podía comprobar la orden de nombramiento del discussor, para evitar falsificaciones (CJ. 1,4,26,1).

3) Se prohíbe comprar bienes en la provincia en que desarrollan sus funciones, ya sea directamente, ya a través de persona interpuesta, a los encargados de actividades de investigación o de comprobación de las valoraciones para los impuestos -quibus vel discussionis indago vel negotium censuale mandatur mientras tengan su estancia en dicha provincia, al igual que se hacía respecto a otros funcionarios (C.Th. 8,15,5,1) ${ }^{103}$. La prohibición se extiende a los asesores del gobernador, abogados del fisco, jefes y secretarios de la chancillería, funcionarios de prisiones oficiales y munícipes de las ciudades, apparitores y decuriones encargados de la recaudación de impuestos y personas encargadas de cualquier investigación o administración de la valoración de los impuestos, y jefes decuriones enviados para la regulación general para todas las valoraciones de impuestos y curadores

Esta lista de funcionarios contemplada en el Codex Theodosianus, tal y como destaca Godofredo, tiene un carácter cerrado, no alcanzando a los simples oficiales, respecto a los cuales la prohibición de comerciar supondría una auténtica iniquidad.

\section{RÉGIMEN SANCIONADOR}

Las principales actividades de los discussores que la legislación imperial tipifica son las siguientes:

1) Realización injusta de una revisión de cuentas, no pudiendo probar la verdad del hecho (C.Th. 11,26,1= CJ. 10,30,1 ${ }^{104}$ ). La injusticia de la revisión podía consistir tanto en inscribir como deudor público a aquel que no lo era como en dar a su patrimonio más valor

\footnotetext{
${ }^{102}$ CJ. 1,4,26,1 Omnem vero libertatem adimimus nostris praesidibus mittendi in agros discussores, seu rationatores, aut exaequatores ad publicarum rationum inquisitionem (...)

${ }^{103}$ Se trata de una constitución de Valentiniano y Valente de fecha incierta, dirigida a Probo, Prefecto del Pretorio: Idem aa. ad Probum praefectum praetorio. Nemo in provincia quam tuetur, donec in eadem commorabitur, aliquid comparandi sumat adfectum: similiter administrantium socii adque participes, quaedam enim uniuscuiusque portio videtur adsessor. Patronos etiam fisci ab his contractibus iubemus inhiberi et qui principatum officiorum gerunt seu corniculum quique commentariensium nomine exosa miseris claustra custodiunt tabularios quoque provinciarum et urbium singularum pari condicione constringimus; identidem numerarii praefecturae vel vicariae potestatis observent. Praeterea officiales adque municipes, qui exactiones quascumque susceperint, eos etiam, quibus vel discussionis indago vel negotium censuale mandatur, insuper principales, a quibus distributionum omnium forma procedit, curatores etiam lex ista contineat. Sobre las consecuencias derivadas de la infracción de esta norma, vid. infra, "Régimen sancionador".

${ }^{104}$ CJ. 10.30.1 Imperatores Valentinianus, Valens, Gratianus. Quotiens in discrepatione constiterit inique discussionem fuisse confectam et fidem facti non poterit approbare discussor, ipse in eodem titulo et in eodem modo ad solvendum protinus urgeatur, in quo alterum perperam fecerit debitorem. VALENTIN. VALENS ET GRAT. AAA. AD ARTHEMIUM VIC. HISPANIARUM. A 369 D. PRID. ID. maio VALENTINIANO NP. ET VICTORE CONSS. A juicio de CUIACIO, op. cit., p. 94 con la expresión "in eodem titulo" la constitución parece estar pensando en oro o en plata, $y$ al señalar "in eodem modo" se refiere a la misma cantidad.
} 
del real, para que por este motivo tuviera que pagar más impuestos ${ }^{105}$. La sanción que establecen para tal conducta los emperadores Valentiniano y Valente, en esta constitución promulgada en el año 369, consiste en condenar a hacer pagar al discussor lo mismo que a su vez él hubiera hecho a pagar a otro.

Baldo de Ubaldis ${ }^{106}$ indica que la ley se basa en el mismo argumento que las disposiciones que sancionan a los árbitros que hacen suyo el objeto del ligitio. Respecto a la acción a través de la cual ha de encauzarse la reclamación, el mismo jurista entiende que además de poderse ejercitar la acción por cuasidelito, como en el caso de jueces y árbitros, también se podría proceder contra ellos como si se tratase de cuasi gerentes de un negocio o mandato ${ }^{107}$.

La doctrina señala que la reclamación habrá de dirigirse ante el superior jerárquico, como se dispone en CJ. 11.58,6. Godofredo concreta que la apelación de la decisión o sentencia statuto seu sententia-del discussor, debe realizarse ante el Vicarius o Praefectus Urbi o ante el Comes Rerum Privatarum -CTh. 11, 30,45-.

Por lo que se refiere a la carga de la prueba, dice Bartolo de Sassoferrato ${ }^{108}$ que corresponde al funcionario que hizo la estimación o la medida. De idéntica opinión es Brunneman ${ }^{109}$, estableciendo una analogía con el supuesto de la estimación de los bienes del pupilo (D. $27,8,1,13)^{110}$. Puntualiza Godofredo ${ }^{111}$ que corresponde al discussor probar que la revisión de cuentas por él realizada fue correcta y frente a ello, corresponderá a los provinciales que lo refutan demostrar a través de recibos o de otra manera la iniquidad de la revisión, pues, tal y como se dice en CJ 11,58,5, quien se queja de haber sido gravado injustamente por los peraequatores debe probarlo.

2) Defraudación al erario público. Para estos casos solía establecerse una pena al cuádruplo, ya a partir de una constitución de Arcadio y Honorio del año 396 que nos trasmite CTh $13,11,8^{112}$ (= CJ. 11,57,6), donde se establece para los peraequatores y discussores reos de negligencia o favoritismo -culpam negligentia vel gratia- la condena a pagar el cuádruplo de las annonas, además de pérdida de honores. Se añade que lo recibido en perjuicio de los provincianos habrá de ser pagado al cuádruplo.

Diez años más tarde, los mismos emperadores promulgan nueva constitución en la que afirman haber tenido noticia de que en el último quinquenio muchos comites, peraequatores y discussores habían sido enviados a provincias sin que su actuación beneficiara lo más minimo al bienestar público. Por ello ordenan al Prefecto del Pretorio Longiniano que, si tiene conocimiento

${ }^{105}$ ACCURSII, Glossa in Volumen, "Corpus Glossatorum Juris Civilis”, Augustae Taurinorum, ex Officina Erasmiana, 1969, p. 344, gl. confectam.

${ }^{106}$ BALdo Degli UbALDI, Commentaria in VII. VIII. IX. X. \& XI. Codicis libros. Summa studio \& labora collatis vetustissimis exemplaribus innumeris proprementis purgata, Lugduni, 1585, fol. 296, ad. l. quoties.

${ }^{107}$ Entiende BALDO DE UBALDIS que no hay que hacer distinción en función de la persona que haya elegido a ese juez o árbitro, y ello aplicando D. 17,1,6,4 (Ulp., 1. XXXI ad ed.), donde se afirma que procede la acción de mandato tanto en el caso de que la actuación del mandatario sea en interés del mandante como si lo es en beneficio de un tercero. Por lo que se refire a la mención de la actio negotiorum gestorum, hay que recordar, como hace CUQ, Études...cit., p. 47 que Ulpiano permite ejercitar esta acción contra el juez que no ha tenido en cuenta una causa de compensación (D. 3,5,8 (7),2, Ulp. 1. X ad. ed.).

${ }^{108}$ Bartoli commentaria in tres libros codicis, Lugduni, 1549, fol. 18 (ad CJ. 10,30,1).

${ }^{109}$ BRUNNEMANI, op. cit., p. 1194-1195.

${ }^{110}$ Según el texto citado no incumbe al pupilo la prueba para demostrar que los fiadores no fueron solventes cuando fueron aceptados, sino a los magistrados, para demostrar que aquellos fueron solventes.

${ }^{111}$ GOTHOFREDI, op. cit., t. IV, p. 195.

${ }^{112}$ C. Th. 13,11,8 (Impp. Arcadius et Honorius) aa. Eusebio praefecto praetorio. Peraequatores ac discussores, quorum nobis data sunt nomina, si incurrerint culpam neglegentiae vel gratiae, non solum honorum iacturam, verum etiam annonarum in quadruplum multam subire debebunt, ea vero, quae in damnum provincialium fuerint accepisse convicti, in quadruplum cogentur exsolvere. Dat. IIII kal. april. Mediolano Arcadio IIII et Honorio III aa. conss. (396) 
de que alguno de estos funcionarios ha desempeñado negligentemente sus tareas, deberá enviar al emperador sus credenciales y hacerle devolver el doble de los emolumentos obtenidos. Si se descubre que alguno ha extorsionado a los provinciales, deberá obligarsele a devolver el cuádruplo (CTh. 13,11,11) ${ }^{113}$.

Posteriormente, Justiniano dispondrá que el culpable de defraudación al fisco, con o sin consentimiento del contribuyente -sive volentibus sive invitis- habrá de ingresar en las cuentas públicas el cuádruplo de lo defraudado, además de sufrir la pena correspondiente al delito de concusión (CJ. 10,30,4,4) ${ }^{114}$. Al contribuyente que hubiere dado el dinero se le dispensará el mismo tratamiento que a quien hubiere confesado ser deudor de las deudas del fisco, estando obligado a ingresar nuevamente la cantidad sobre la que versaba la cuestión en las cuentas públicas.

A pesar de que para estos casos era habitual la imposición de la pena al cuádruplo -sin perjuicio de otras consecuencias-, Valentiniano III había llegado a disponer que cualquier palatinus que hubiere exigido mayores sumas de las que figuraban en las listas que se les entregaban sería acusado de sacrilegio ${ }^{115}$ y proscrito (Nov. Val. $\left.7,1,1\right)^{116}$.

3) Cobrar por emitir los resguardos liberatorios a los contribuyentes. Los emperadores Graciano, Valentiniano y Valente, en el año 383 establecen en una constitución que recoge C.Th. 12,6,18 la misma pena que en el caso anterior: cuádruplo del valor de lo que les hubiere dado el contribuyente ${ }^{117}$. La norma se repite en el Edictum Theodorici, c. $144^{118}$.

${ }^{113}$ CTh. 13,11,11 Idem aaa. Longiniano praefecto praetorio. Per hoc quinquennium multos comites ac peraequatores nec non etiam discussores per diversas provincias constat esse directos, quos nihil profuisse utilitatibus publicis cognovimus. Ideoque sublimitas tua eorum actus diligenti examinatione perpendat et si quos neglegenter invenerit iniuncta curasse, ablatis codicillis primitus et refusis faciet in duplum quae perceperunt emolumenta redhibere. Si quos vero rapacitate plectenda a provincialibus aliquid abstulisse constiterit, direpta in quadruplum redhibere compellas. Dat. Vid. feb. Ravennae Arcadio a. VI et Probo conss. (406).

${ }^{114}$ CJ. 10,30,4,4 ...Sed si ab iis, qui in provincias sunt, sive volentibus sive invitis, vel unum obolum acceperit, ipse quiden restituat, quod acceperit, quadruplum publicis rationibus inferre cogendus, ep poenam a principe infligendam experiatur, quasi proditor fisci et collatorum concussor. La concussio sería la exactio per vim facta, como indica ERNOUTMEILlET, op. cit., p. 553, aplicada especialmente a las exacciones cometidas por soldados. TORRENT, A., Diccionario de Derecho Romano, Edisofer, Madrid, 2005, p. 197, define la concussio como conducta delictiva de magistrados y funcionarios públicos consistente en la extorsión de dinero a particulares con la amenaza de realizar o abstenerse de actos de su competencia, siendo una figura agravada de concusión el crimen repetundarum. Señala MOMMSEN, T., Derecho penal romano, trad. P. Dorado, Temis, Bogotá, 1976, p. 447, que, a partir del siglo II d.C., sin que por ello quedara proscrito el procedimiento repetundarum, la extorsión fue considerada como un delito independiente, formando con ella el delito de concussio, de intimidación, consistente en constreñir a alguien a dar o prestar algo, abusando al efecto del poder oficial que el opresor tenía en sus manos. Del delito de concusión se ocupa el D. 47,13, además de diversas rúbricas del Codex de Justiniano relativas a las concusiones efectuadas por diversos funcionarios.

${ }^{115}$ Anota PHARR, op. cit., p. 521, n. 5 y p. 593, que la condena por sacrilegio -definido por MOMMSEN, op. cit., p. 458, como "apropiación de los bienes de los dioses"- se produce como consecuencia de la violación de las leyes sagradas del emperador, considerado como una divinidad.

${ }^{116}$ Nov. Val. 7,1,1...sacrilegii percellendis reatu, proscriptionis etiam supplicioque dedendis, cum huiusmodi usurpationem probatio confutarit

${ }^{117}$ C. Th. 12.6.18. Idem aa. Flaviano proconsuli Asiae. Quisquis posthac, quem exactionis vel susceptionis provincia manet, non specialiter et quid et in qua specie et ex quibus titulis et pro qua indictione videatur accepisse rescripserit, quadrupli eius rei, quam debitor dedisse se dicit, illatione multetur. Officium quoque, nisi ad fraudes, si forte deinceps iteratae fuerint, detegendas....tale commissum et inquisitioni subiaceat. Dat. VI id. maio Constantinopoli Merobaude II et Saturnino conss.

${ }^{118} \mathrm{E}$. Th. 144. De emittendis securitatibus fiscalium titulorum.Quicunque susceptores fuerint fiscalium titulorum, in emittendis possessorum securitatibus nomina singularum possessionum, professionem earum evidenter designent : acceptam quoque pro earum functione exponant pecuniae quantitatem. Quod si aliquis professionem locorum, nomina summamque praeceptae pecuniae, in securitatibus a se factis comprehendere forte noluerit, et huius culpae reus in iudicio fuerit adprobatus, quadruplum eius pecuniae, quam possessor se dedisse probaverit, eidem cogatur exsolvere. 
Justiniano otorga a los ciudadanos el derecho a repeler la concusión y a solicitar al emperador el envío de persona con facultades para sancionar al autor de la extorsión (CJ. 10,30,4,5 in (ine $)^{119}$

4) Importunar a los notarios retirados con censos, revisiones, igualas etc. El CJ. 12,7,1 decreta la expulsión del cuerpo de contadores y la imposición de una cuantiosa multa gravis multae- aún sin concretar la cuantía, al funcionario - principalmente del officium del Prefecto del Pretorio- que incurra en la conducta descrita. La pena se impondrá aun en los casos de culpa leve ${ }^{120}$.

5) Realización de revisiones careciendo de habilitación legal para ello. La constitución del emperador Zenón recogida en CJ. 8,13(12),2121 contempla el examen de rentas u obras públicas efectuadas con fondos municipales o por la liberalidad de los particulares ordenado por el gobernador provincial -o por el resto de los funcionarios mencionados en la constitución- contraviniendo la prohibición que en la misma se establecía. Se tipificaba igualmente la reclamación de la vigésima cuarta parte de los gastos efectuados en las obras. Las penas variaban en función del funcionario que las cometía:

a. Los cinco primeros oficiales del gobernador de la provincia: destierro perpetuo y confiscación de bienes en favor de la ciudad a la que hubieren lesionado.

b. Gobernador de provincia: multa de cincuenta libras de oro.

c. Jueces y sus oficiales: la misma pena que en el caso anterior.

6) Las consecuencias señaladas en C.Th. 8,15,5,2-3 $3^{122}$ para el caso de adquisición de bienes en la provincia en la que desarrollan su actividad por parte de los funcionarios contemplados en la propia constitución, entre ellos los discussores, en contravención de la prohibición contenida en la norma son tres:

- Revocabilidad de la transacción efectuada, con derecho a perseguir la cosa vendida de cualquiera que la tenga en su poder, en caso de nueva transmisión.

Quod etiam circa discussores similiter convenit custodire, si de quibus titulis quas summas a praesumptoribus vel reliquatoribus exegerint, in securitatibus emittendis signare noluerint.

${ }^{119}$ CJ. 10,30,4,5 : ...Neque vero pro securitate a se exposita quidquam accipiat discussor, se si quid accipere ausus fuerit, licentiam habeant possessores atque cives tam repellendi eius concussionem, quam supplicationibus adeundi principem, ut in eam regionem aliquem mittat, qui poenam debeat ei infligere, qui aliquid extorquere tentavit.

${ }^{120}$ CJ. 12, 7, 1. Et si quis ex officio vel praecipue sublimitatis tuae temerarius ad census discussiones peraequationes, aliam denique ullam rem inquietator extiterit, officium suum noverit vel levis culpae offensione detecta gravis multae discrimine fatigandum et numerariorum corpus extincto iniuriae auctore minuendum. * GRAT. VALENTIN. ET THEODOS. AAA. EUTROPIO p. *A 380 D.XVII K.IUL.THESSALONICAE GRATIANO VET THEODOSIO AA. CONSS.

${ }^{121}$ CJ. 8,13(12),2. Quod si vir clarissimus provinciae moderator vel eius officium reditus publicos vel opera publica contra vetitum discutiendo vel unam siliquam aut quodlibet ex isdem reditibus vel operibus vindicando sacratissimae nostrae legis praecepta transierint, quinque quidem officii primates exilio damnati perpetuo bona sua civitati quam laeserint non dubitent vindicanda, rector vero provinciae quinquaginta librarum auri ferietur dispendio: hac eadem poena spectabilibus quoque iudicibus, licet illustri dignitate fuerint decorati, et eorum officiis, sicut superius distinctum est, imminenda. * ZENO A. ARCADIO p. *A 485-486?

${ }^{122}$ C.Th. 8,15,5,2. Verum si qui ex his medio muneris sui tempore vel privatim aliquid emisse vel publice detegetur, in irritum gesta revocentur, comparatores autem contra interdicta.....mati non modo his, quae per semet ipsos vel per aliam fuerint empta personam, sive agri sint sive domus sive mancipia seu quaecumque mobilia, sed etiam ea pecuniae taxatione, quam dederint, exuantur. Nec ullus inquirat, utrum civiliter rem actam constet an turbide. Nec obsit propria reposcenti vel venditio interiecta vel largitas vel mentio ulla legati, nam utcumque in alterum res fuerit a comparatore translata, quam emi in officio non oportuit, liberum corporis persequendi praestamus arbitrium. 3. Adiungimus autem, ut, si domini corporum venditorum, postquam emptores coeperint esse privati, quinquennio integro in repetitione cessaverint, continuo sibi fiscus usurpet, quae contra hoc vetitum vendita docebuntur. 
- El funcionario perdería el precio pagado.

- Si pasaran cinco años tras el cese del funcionario en el cargo sin que se reivindique el bien en cuestión, este pasaría al Fisco.

7) Por otra parte, según recuerda Accursio, la palabra discussor a veces se emplea en las fuentes como sinónimo de recaudador - exactor- desacreditado, como ocurre en la constitución de Alejandro Severo que nos trasmite el CJ. 6,2,8, según la cual, se podrá interponer acción de hurto contra el recaudador de tributos que, sabiendo que nada se debía, una vez realizado el pago por el contribuyente, se hubiera llevado y vendido una esclava de este. Además, resultando imposible la usucapión por parte del comprador, al tratarse de una cosa hurtada, sería posible la reivindicación del dueño ${ }^{123}$.

\section{LOS DISCUSSORES TRAS LA CAÍDA DEL IMPERIO ROMANO DE OC- CIDENTE}

En Bizancio la figura del logoteta ${ }^{124}$ se mantuvo a lo largo de los siglos. En general se les considera agentes del fisco, encargados especialmente del ingreso de los impuestos y de la verificación de las cuentas de las diversas administraciones, así como del control de los pagos realizados por el estado para los sueldos y tratos diversos.

Sin embargo, la doctrina no se pone de acuerdo a la hora de determinar cuáles fueron los antecesores de estos funcionarios, pues mientras algunos consideran como tales a los scrinarii ${ }^{125}$ vinculados al Prefecto del Pretorio, encargados de la vigilancia financiera de la Administración, para otros serían los numerarii ${ }^{126}$, los rationalis $^{127}$ o los discussores ${ }^{128}$.

Pero al mismo tiempo que se mantenían sus funciones de inspección e intervención fiscal, se asiste a una diversificación y especialización de sus funciones, especialmente a partir del siglo

${ }^{123}$ CJ. 6.2.8. Imperator Alexander Severus. Etiam furti actione tributorum exactor tenetur, si non cessante te in tributoria exactione sciens, quod nihil deberetur, ancillam tui iuris abduxit aut vendidit. Quae res facit, ut nec emptor usucaperet vindicatioque tibi ipsius competat. ALEX. A. VALENTI. A 231 p. X K. MART. POMPEIANO ET PELIGNO CONSS.

${ }^{124}$ Sobre estos funcionarios en el Imperio bizantino puede destacarse la siguiente bibliografía: GuILLAND, R., «Les logothètes: Ėtudes sur l'histoire administrative de l'Empire byzantin», Revue des études byzantines, 29, 1971, p. 5 y ss.; EVANS, J.A.S., The age of Justinian: the circunstances of imperial power, Routledge, London, 1966; STEIN, R., Studien zur Geschichte des byzantinischen Reiches vornehmlich unter den Kaisern Justinus II u. Tiberius Constantinus, J. B. Metzlersche Verlagsbuchhandlung, Stuttgart, 1919; BURY, J.B., «The Imperial Administrative System in the Ninth Century: With a Revised Text of Kletorologion of Philotheos», Oxford U.P., 1911; KAZHDAN, A.P., Oxford Dictionary of Byzantium, Oxford University Press, 2005; SEMENov, A., «Über Ursprung und Bedeutung des Amtes der Logotheten in Byzanz», Byzantynische Zeitschrift, 19 (1910), p. 440-449 y BRÉHIER, L., Las instituciones del Imperio Bizantino, trad. J. Almoina, Unión Tipográfica Editorial Hispano Americana, Mexico, 1956, p. 224 y ss.

${ }^{125}$ STEIN, op. cit., p. 139.

${ }^{126}$ Así para BuRY, p. 71, es posible que el logoteta del Pretorio descienda de un contable en la oficina del Prefecto del pretorio, quizá el jefe de los numerarii (Not. Dig. Occ. IV. 24).

${ }^{127}$ GuILland, op. cit., p. 5. El autor sitúa la aparición de los logotetas a fines del siglo V, con Anastasio I. Considera que en estos primeros tiempos los logotetas serían simples agentes ejecutivos del Fisco, vinculados a la Prefectura del Pretorio; todavía bajo Justiniano no gozarían del rango de ministros y serían enviados en diversas misiones a provincias. A partir del siglo VII su importancia crecería enormemente, alcanzado el rango de ministros y estando afectos a los diversos servicios financieros del Estado. Es cierto que en varias disposiciones imperiales se menciona a la vez a ambos funcionarios-discussoris vel rationalis-: CTh. 11,30,33 y 11, 30, 45; CJ. 7,62,26.

${ }^{128}$ Godofredo, Codex Theodosianus, cit., p. 194, para quien los discussores distan de los rationaliis todo el cielo -toto coelo-. Muchos autores identifican a discussores y logotetas: AGUSTín, A., "Constitutionum Graecarum Codicis Justiniani Collectio et Interpretatio", Opera Omnia, vol II, Typis Josephi Rochii, Lucae, 1766, p. 245- nemo logothetas, sive discussor ...-; SEECK, op. cit., p. 1184, Du CANGE, op. cit., t. V, col. 137c, voz "logotheta"; Di SEGNI, L. "Metropolis and Privincia in Byzantine Palestine", Caesarea Maritima: a retrospective after two millennia, ed. Avner Rabban- Kenneth G. Holum, Leiden-New York-London, 1996, p, 585 n. 52. 
VII, cuando la oficina del Praefectum Praetorium pierde importancia y los distintos departamentos adquieren independencia. De este modo, se conoce el logoteta del Tesoro Público ${ }^{129}$, el logoteta del ejército ${ }^{130}$, el logoteta del dromo ${ }^{131}$, el logoteta del Pretorio ${ }^{132}$, el logoteta secreto ${ }^{133}$, el logoteta del Tesoro Privado ${ }^{134}$ y el Gran Logoteta ${ }^{135}$. Se mencionan también el logoteta de gana$\operatorname{dos}^{136}$ y el de aguas ${ }^{137}$. Incluso existieron logotetas en el seno de la Iglesia Bizantina ${ }^{138}$.

En Occidente, el sistema de inspección y administración fiscal romano fue mantenido por algunos pueblos germanos tras el 476 d.C.

Por lo que se refiere a los ostrogodos, Cassiodoro, consejero de Teodorico I, refleja la existencia de inspectores fiscales -discussores- en varias de sus cartas, correspondiendo su nombramiento en esta época, a juicio de Seeck, al Prefecto del Pretorio ${ }^{139}$.

De este modo, en Var. 1,21 queda constancia de cómo Teodorico se dirige a Maximiano viro illustris y a Andrea, viro senatori, para ordenar la realización de una auditoría -discuterecon la finalidad de comprobar que el dinero por él entregado para el embellecimiento de la ciudad no había sido malversado, en cuyo caso habría de ser devuelto ${ }^{140}$. Más adelante, felicita a Artemidoro, Praefectus urbis, porque en la investigación -discussio-sobre el empleo del dinero destinado a la reconstrucción de las murallas, reveló la existencia de malversaciones, en lugar de haber tratado de ocultarla. En este caso, el emperador se inclina por la clemencia, disponiendo

${ }^{129}$ También conocidos como logotethes tou genikou; serían los herederos, según GuILLAND, op. cit., p. 11, de las principales funciones del comes sacrorum largitionum, a modo de un verdadero ministro de finanzas.

${ }^{130}$ Se trata, siguiendo a GUILLAND, op. cit., p 25, del antiguo rationalis aerarii militairs o rationalis fisci militaris, correspondiente al procurator castrensis romano. KAHRZAN, op. cit. p. 1248 y BURY, op. cit., p. 90 sitúan este funcionario en el siglo VII, cuando se forma una caja independiente para el ejército. Estaría encargado de la paga y aprovisionamiento del ejército; a partir del siglo XI asumiría funciones judiciales. Su cargo desaparecería tras el 1088.

${ }^{131}$ A pesar de que, como refiere SEMENOV, op. cit., p. 448, algunos consideraban a este funcionario como administrador del hipódromo, la mayoría lo vincula con la organización del cursus publicus romano (KAZHDAN, op. cit., voz "logothetes tou dromou"; GuIlland, cit., p. 33; BURY, op. cit., p. 9, SEMENOV, loc. ult. cit.). La figura surge en el siglo VIII, cuando se encomienda a un funcionario único e independiente el servicio de postas - en tiempos vinculada a la Prefectura del Pretorio- además de ocuparse de tareas protocolarias, de la protección del emperador y de la supervisión de las relaciones exteriores.

${ }^{132}$ Coadjutor del Eparca de la ciudad, según KAZHDAN, op. cit., p. 113. BURY, op. cit., p. 71, lo relaciona con el jefe de los numerarii -vid. supra, n. 109 - e infiere que sus funciones estaban relacionadas con la administración de justicia.

${ }^{133}$ GuILlAND, op. cit., p. 75, traduce como "logoteta de los ministerios y oficinas". Este funcionario -mencionado por primera vez bajo el reinado de Alejandro Conmeno en 1081 -ejerce su autoridad, además de sobre las finanzas, sobre el conjunto de la administración civil.

${ }^{134}$ Sucesor del comes rerum privatorum (GuILLAND, op. cit., p. 85), encargado de administrar los bienes integrantes del patrimonio privado del emperador.

${ }^{135}$ Sucesor del logoteta secreto (GUILLAND, p. 101).

${ }^{136}$ Responsable de los caballos y mulas para el ejército y el cursus publicus.

${ }^{137}$ Según SEMENOV, le corresponderían las tareas de irrigación artificial (por ejemplo, a través de canales). KAZHDAN, op. cit., p. 1247 lo identifica con el comes hydaton.

${ }^{138}$ GuILLAND, op. cit., p. 9, quien asimila sus funciones a las del logoteta del dromo; SEMENOv, op. cit., p. 446-447, quien llega a la conclusión que los logotetas sacros sobrevivieron al imperio bizantino, apoyándose en las observaciones del monje Paulo en su obra "Über Ämter und Institutionem die Verwaltung der orientalischen Kirche bettrefend", St. Petesbourg, en 1857, relativa a las oficinas e instituciones en la administración de la iglesia oriental, donde se refiere a los logotetas del Patriarca de Constantinopla como encargados de la supervisión de los ingresos, de la sanción de las cuentas y como superiores del departamento jurídico.

${ }^{139}$ SEECK op. cit., p. 1.184, se apoya, para esta conclusión, en Cass. Var. 12,2,2. Se trata de una carta del 534-535 d.C. en la que el propio Cassiodoro, como Prefecto del Pretorio, se dirige a todos los jueces de provincias, manifestando que durante su mandato hizo que fueran ignorados los terrores de los discussores y no realizó indagaciones extraordinarias, puesto que optó por ser conducido lentamente por las leyes: discussorum terrores fecimus ignorari. nec extraordinaria quaesivimus, qui cuncta geri legibus optabamus.

${ }^{140}$ Cass., Var. 1,21: ...Quocirca praesenti decernimus jussione, Romanae civitatis fabricas vos debere discutere, si labor operis concordat expensis: vel si apud aliquem constet residere pecuniam que non sit fabricis expensa, deputatae rei reddat erogandam ... (CASSIODORI, M.A., Opera Omnia in duos tomos distributa, t. I, Rotomani, 1679, p. 12) 
que los responsables únicamente tengan que devolver aquello de lo que se han apropiado deshonestamente, sin imponer multas adicionales, pues considera que será suficiente castigo tener que renunciar a aquello que habían desvalijado, considerándolo ya como suyo ${ }^{141}$.

En ambos casos puede comprobarse como Teodorico emplea a altos funcionarios para la inspección de las cuentas correspondientes a las obras públicas, al igual que se hacía en la época romana.

También las funciones de los discussores como inspectores de impuestos o revisores del censo $^{142}$ perviven en la época ostrogoda, y así Teodorico da noticia de las quejas de los habitantes de Gravasi y Ponto contra las exacciones de los discussores Probus y Januarius, alegando que su tierra es pobre y de que no pueden hacer frente a los tributos que se les han impuesto. Por lo tanto, ordena que no se les haga pagar más de lo que hacían en tiempos de Odoacro $^{143}$.

Se menciona, por último, el nombramiento en cierta ocasión un discussor para comprobar los ingresos procedentes de los derechos de aduana y de minas de hierro ${ }^{144}$.

En el reino franco, en el Edicto de Clodoveo II del 615 se dispone que, si los obispos o los grandes propietarios poseen bienes en más de una provincia, los jueces o inspectores -discussores- a cuya jurisdicción están sometidos no pueden ser más que lugar donde se encuentran los bienes $^{145}$.

Por lo que se refiere a España, según Thomson ${ }^{146}$, el método de administración de justicia y de recaudación de impuestos en la época visigoda, al menos hasta el nivel del gobernador

${ }^{141}$ Cass., Var., 2,34: ... Atque ideo universa pecunia, quae fuerat fabricis deputata Romanis, \&nunc Magnitudinis tuae a disscussione constirit abjuratam, cum nec reddita suo tempore, nec docetut expera, sine aliqua dilatione resumatur, \&vobis ordinantibus iterum Romanis moenibus applicetur. Nefas este nim, ut in alios usus trnaseant que sibi substracta non immerito Roma suspirat ... Sed assuit moderatrix, Semper que novis est juncta, clementia: ne indecore facta plectamus graviter incitante justitia. Sufficiat nobis cupiditatem non implesse, quod voluit. Nec major potest provenire vindicta, quando velut propria videtut perdere, qui se suppressa turpiter judicaverat possidere.

${ }^{142}$ Esta función aparece clara en Cass. Var. 9, 10, 4, donde en el marco de una remisión de impuestos a los sicilianos indica va a ordenar a los discussores del censo que todo lo que hayan pagado por este capítulo para la quinta indicción (526-527) lo apunten pagado a cuenta: Sed ut latius extendatur nostra clementia suavemque dominum impensis beneficiis sentiatis, quicquid a discussoribus novi census per quintam indictionem probatur affixum, ad nostram eos fecimus deferre notitiam, ut, quod rationabile fuerit aestimatum, libentibus animis perferatis, quia nullum laedit observata iustitia

${ }^{143}$ Cass. Var., 4,38 ... Proinde illustris Magnitudo tuae Gravasianos, atque Pontonates nobis supplicasse cognoscat, a Januario sed \& Probo discussoribus iniquis se oneribus ingravatos; cum sterilitas jejuna locorum nulla sibi augmenta fieri pariatur ... Atque iodeo consuetudinem eis pristinam censemus ese revocuanda, ut sicut Odoacris tempore tributa solverunt... impuesto Algo parecido sucede en Cass. Var. 9.10. En todos estos casos, concluye GoDOFREDO, Codex Theodosianus, t. IV, cit., p. 194, los discussores tienen la facultad de afligir con el censo una superindictio o aumentar su importe. La superindictio consistía en una tasa extraordinaria añadida a la cuota normal del impuesto. Había de incluirse una indicación acerca de su finalidad y podía ser acordada por el emperador o en caso de urgencia, por el Prefecto del Pretorio (HuMBERT, op. cit., p. 189. n. 1 y 263 y APARICIO PÉREZ, op. cit., p. 520 y 171; C.Th. 11,6,1 y 11.16.8).

${ }^{144}$ Cass, Var. 3, 25 ...Praeterea ferrarias praedictae Dalmatiae cuniculo te venitatis iubemus inquirere, ubi rigorem ferri parturit terrena mollities et igne decoquitur, ut in duritiam transferatur. hinc auxiliante deo patriae defensio venit: hinc agrorum utilitas procuratur et in usus humanae vitae multiplici commoditate porrigitur. auro ipsi imperat et servire cogit locupletes pauperibus constanter armatis. convenit itaque hanc speciem diligenti indagatione rimari, per quam et nobis generantur lucra et hostibus procurantur exitia. esto ergo de antefata discussione sollicitus et in publicis utilitatibus temperatus, ut nostrum rationabile compendium crescendi tibi procurare possit augmentum. Cfr. SEECK, op. cit., p. 1186.

${ }^{145}$ Edictum Chlotharii II. Regis in Concilio Parisiensi V datum anno DCXV, XIX. Episcopi vero vel potentes, qui in aliis possidente regionibus, judices vel missos discussores de aliis provinciis non instituant nisi de loco, qui justitiam percipiant \& aliis reddant, recogido por BALUZIUS, S., Capitulario Regum Francorum, t. I, Parisiis, 1677 (Cfr. CLAMAGERAN, op. cit., p. 134).

${ }^{146}$ Thomson, E. A., Los godos en España, trad. Javier Faci, Alianza Editorial, Madrid, 1971, p. 153. (GARCÍA DE VALDeAvelano, L., Curso de Historia de las Instituciones españolas, ed. Revista de Occidente, Madrid, 1973, p. 212; 
provincial, continuó siendo lo que había sido en tiempos romanos. Según el mismo autor, la autoridad central continuó enviando funcionarios de sus consejos para recaudar los atrasos compulsores- y los discussores para mantener toda la maquinaria de recaudación de impuestos en buen funcionamiento.

Parece ser que el abuso consistente en pedir recibos por pagos ya realizados, antaño realizada por los discussores, se sigue cometiendo en época visigoda esta vez de mano de los exactores, es decir, de los funcionarios municipales ahora encargados de supervisar la recaudación de los impuestos ${ }^{147}$.

Tenemos, además, constancia de la existencia de unos funcionarios, denominados discussores iuramenti, enviados por el nuevo Rey a los pueblos con la misión de supervisar el juramento de fidelidad al rey ${ }^{148}$, tal y como se deduce de una Ley de Égica que nos trasmite la Lex Romana Wisigothorum, 2,1,7 ${ }^{149}$. Efectivamente, en dicha ley se castigaba con "pena no leve" a quienes diferían el juramente de fidelidad o, si ejercían en un cargo en palacio, se negaban a comparecer ante el príncipe - pues, a diferencia del resto de los súbditos, los magnates del Aula Regia tenían que prestar el juramento de fidelidad ante el propio Monarca en la ceremonia de la elevación real ${ }^{150}$.

Si cualquier persona libre tenía conocimiento de la elección del príncipe y buscaba excusas o se retrasaba dolosamente a prestar el juramento cuando la autoridad encargada de su supervisión - el discussor ${ }^{151}$ - acudía al lugar de su residencia, el rey podía ordenar lo que quisiera de su persona y sus bienes:

LV 2,1,7...si quis sane ingenuorum de sublimatione principali cognoverit et, dum discussor iuramenti in territorio illo accesserit, ubi eum habitare constiterit, quesita occasione se fraudulenter distulerit in eo, ut pro fide regia conservanda iuramenti se vinculo alliget, aut ille, qui, sicut primisimus, ex ordine palatino fuerit, minime regis

Díaz Martínez, P.C., Martínez MaZA, C y SAnz Huesma, F.J., Hispania tardoantigua y visigoda, ed. Istmo, Madrid, 2007, p. 451).

${ }^{147}$ THOMSON, op. cit., p. 151. Los exactores eran elegidos anualmente por la curia municipal de entre sus miembros por un periodo de dos años. Señala la doctrina el contraste entre los principios que regían la imposición, según se desprende de los cánones conciliarios -principios de economía, de no excesiva presión fiscal y de utilitas publica-, y la realidad de los abusos por parte de la monarquía y de particulares, que en ocasiones condujeron a la adopción de algunas medidas de amnistía (Cfr. PÉREZ PrENDES MuÑOZ-ARRACO, Historia del Derecho Español, I, S.P.U. Complutense de Madrid, Madrid, 1999, p. 544) y a establecer, en el canon XVIII del III Concilio de Toledo, la competencia de los obispos para inspeccionar la forma en que eran tratados los contribuyentes y dar parte de los abusos (GARCÍA DE VAldeAvellano, op. cit., p. 213; DíAZ MARTínEZ-MARTínEZ MAZA-SANZ HuESMA, op. cit., p. 454; GARCÍA Moreno, L. Historia de España visigoda, Cátedra, Madrid, 1989, p. 530).

${ }^{148}$ MingUEZ, J.M. "Sociedad esclavista y sociedad gentilicia”, en "Romanización” y "reconquista” en la Península Ibérica, nuevas perspectivas, ed. Hidalgo-Pérez-Hervás, Ed. Universidad de Salamanca, Salamanca, 1998, p. 285, se encarga de precisar que los discussores actuaban como representantes del monarca, no erigiéndose, en modo alguno, en destinatarios de la fidelidad jurada.

${ }^{149}$ DUMMER SCHEEL, S., "La cuestión judía en España durante el reino visigodo. Acusación de conjura contra el monarca bajo el reinado de Égica (694)", Revista de Historia y Geografía, 20, 2007, p. 107, explica el origen de esta norma en la necesidad del rey Égica, ante la agudización de los enfrentamientos entre clanes y facciones, de asegurarse la fidelidad de los súbditos mediante un riguroso sistema de juramentos, sustituyendo el sistema anterior, en el que el pueblo juraba fidelidad al rey en conjunto y solo los palatinos en forma directa por un nuevo sistema en el que cada habitante del reino debía jurar personalmente la fidelidad ante el monarca ante unos funcionarios: los discussores iuramenti.

${ }^{150}$ García de VALDEAVEllano, op. cit., p. 194-5.

${ }^{151}$ CALVO, C.P., "Consuetudo y mos gothorum en la lex Wisigothorum”, AHDE, 1984, p. 233, destaca el paralelismo entre estos discussores iuramenti y los clérigos enviados por el obispo para comprobar la situación de dependencia efectitva de los libertos de la Iglesia respecto de su perpetua patrona. Por su parte BARBERO, A. -VIGIL, M., La formación del feudalismo en la Península Ibérica, ed. Crítica, Barcelona, 1978, p. 172 señalan que los discussores enviados por el rey tendrían ya sus equivalentes en la organización de la Iglesia visigoda y con los missi carolingios encargados de reclamar la renovación del juramento de fidelidad en el Imperio franco. 
obtutibus se presentandum ingesserit, quicquid de eo vel de omnibus rebus suis principales acutoritas facere vel iudicare voluerit, sui sit incunctanter arbitrii.

Continuaba la ley de Égica señalando que, si no se podía prestar el juramento por enfermedad o por estar ocupado en alguna causa de utilidad pública, se procuraría hacerlo llegar a oídos del monarca en cuanto fuera posible. El incumplimiento de fidelidad de los súbditos era castigado con la excomunión.

A partir del reinado de Juan II van perfilándose las funciones de los contadores reales de cuentas con la promulgación de unas primeras Ordenanzas en 1437, posteriormente refundidas por los Reyes Católicos en 1478. A pesar de que no está claro cuáles son los precedentes exactos de los contadores ${ }^{152}$, algunas de las funciones reguladas en dichas ordenanzas recuerdan a las en su día desarrolladas por los discussores romanos ${ }^{153}$.

A juicio de algunos, no obstante, puede vincularse hasta cierto punto la actividad de los discussores romanos con la de los Contadores Reales de Cuentas. Así lo entiende, por ejemplo, Pérez y López, quien, tras justificar la necesidad de la labor de inspección fiscal en un Estado ${ }^{154}$, afirma que nuestro Derecho toma como modelo para la exacción, administración y distribución de impuestos el modelo de administración romana, estableciendo varios empleos dentro de una escala jerárquica $^{155}$ :

\begin{abstract}
Ha podido muy bien tomarse de los Romanos esta idea de administración: pues ellos establecieron los muchos empleos de rentas baxo los diversos nombres que constan de los títulos del Código que van al frente, y de otros de que se hace mención en sus respectivos lugares. Por sus diferentes grados se ve que eran del Superior los Discursores o Descriptores, los quales tenían también otros nombres, de los que se infiere que eran como unos Inspectores que inspeccionaban y describían en las administraciones y cobranzas de tributos los perjuicios y cosas dignas de enmienda, para que las reformase el Questor principal, cabeza de la misma administración, llamado también cancelario, cuyo nombre y empleo conviene con el que está entre nosotros establecido, y del que se habla en la introducción a las ordenanzas o leyes del $\S 8$ de este
\end{abstract}

${ }^{152}$ Sobre el origen de la intervención fiscal en Castilla, vid. GIBERT y SÁNCHEZ DE LA VEGA, R., "Contadores de Hacienda e intervención fiscal en el antiguo régimen castellano", en Itinerario histórico de la Intervención General del Estado, Instituto de Estudios Fiscales, Madrid, 1976, p. 91 y ss., donde se destaca una relación entre los contadores y la figura del Mayordomo o Mayor de la casa del rey que aparece en las Partidas (Part. 2,9,17); cfr., asimismo GARZÓN PAReja, M., Historia de la Hacienda de España, vol. I, Instituto de Estudios fiscales, Madrid, 1984, p. 71 y ss.

${ }^{153}$ Explica GARCÍA DE VALDEAVELLANO, op. cit., p. 593 y ss., que las Ordenanzas de 1437 "reglamentan la organización y funciones de la Contaduría Mayor de Cuentas, integrada por dos Contadores mayores, sus lugartenientes y los oficiales que llevaban los libros de contabilidad. Con arreglo a dichas ordenanzas los Contadores Mayores debían entender y decidir como jueces en cuantos asuntos, litigios y débitos concernían a las cuentas de la Hacienda regia, verificar la verdad de las declaraciones de cuentas, responder a las peticiones, requerir a los recaudadores y arrendadores de rentas para que rindiesen sus cuentas, cuidar de los libros o registros de la contabilidad e informar al Rey, en cualquier momento que este lo solicitase, del estado general de las cuentas y acerca de las cuentas y acerca de las rentas pendientes de pago". Se trata, en suma, de unas funciones que efectivamente recuerdan a las de los discussores romanos.

${ }^{154}$ PÉREZ Y LÓPEZ, A.X., Teatro de la legislación universal de España é Indias, t. VIII, Madrid, 1794, p. 403: “del mismo modo que no puede excusarse la imposición de tributos, para ocurrir á sus gastos precisos y cargas indispensables, la exacción, administración y distribución de ellos son susceptibles de infinitos fraudes, de los quales no solo pueden originarse graves males á los pueblos en común y á los contribuyentes en particular, sino á los Príncipes en el defalco y abuso de su real Patrimonio. Por tanto, ha sido uno de los primitivos objetos de los Gobiernos, y está siendo continuamente, precaver tan funestos perjuicios para los Príncipes mismos y sus vasallos; estableciendo los medios y reglas mas adaptables, así para que la recolección de las rentas no se haga mas gravosa de lo preciso, como para que se distribuyan estas con el debido destino y el mayor arreglo y economía".

${ }^{155} \mathrm{El}$ mismo sentido se aprecia en la obra suscrita por M.C., Las tardes de Roque Pio y Don Rufo de Alfarache, Oficina de la viuda de Felipe Teruel, Murcia, 1794, p. 125-125: "Los que ahora llamamos contadores, se decían entonces (se refiere a los tiempos romanos) discussores; porque discurrían y reveían las cuentas o racionales, porque las glosaban o adicionaban y tomaban razón de ellas en sus libros. Para la imposición del tributo o censo, los inspectores veían y reconocían los campos o tierras, su esterilidad o fecundidas y su mayor o menor substancia. Los censitores y perequatores distribuían y acomodaban a cada contribuyente la cantidad de su respectivo censo, observando la posible igualdad o proporción según la descripción de los Inspectores". 
artículo; y nuestros Directores generales de las mismas rentas son semejantes a los Discursores Romanos.

\section{CONCLUSIONES}

I. Las fuentes literarias suelen reflejar una imagen bastante negativa de los discussores, apareciendo muchas veces como personajes dispuestos a toda clase de abusos sobre los contribuyentes, aunque habida cuenta del clima de corrupción existente del Bajo Imperio, no serían los únicos en cometerlos. Esta imagen negativa queda especialmente patente en la obra de Procopio de Cesarea, alternándose, sin embargo, las menciones a discussores corruptos y a discussores honrados en las obras de Símaco y Casiodoro.

II. Del análisis de los diversos textos del Código de Justiniano y del Teodosiano relativos a los discussores se desprende la variedad de las tareas encomendadas a estos funcionarios. Ocupa un lugar destacado la labor de inspección fiscal, siendo enviados a provincias para la realización de una inspección extraordinaria de las cuentas y para controlar y compeler a los contribuyentes morosos, labor que queda especialmente reflejada en la Nov. Val. 1,3 .

III. También se les podían asignar otras tareas como la revisión del censo, el examen de las cuentas de las obras públicas, el conocimiento de determinadas causas en materia fiscal, la fijación de los precios del mercado y otras más esporádicas, como la recuperación de terrenos entregados ilegalmente en concesiones de terrae laeticae.

IV.Las constituciones imperiales establecieron diversas medidas para prevenir los posibles abusos de estos funcionarios. Destaca, en este terreno, el establecimiento de la competencia exclusiva de determinados funcionarios, primero, y después del propio emperador para acordar el nombramiento y envío del discussor. Otras medidas consistían en la posibilidad de comprobar la orden de nombramiento, para evitar falsificaciones, y la prohibición de comprar bienes en la provincia en la que este funcionario desempeña sus funciones.

V. A estas medidas acompaña un riguroso régimen sancionador. Cuando se vulneraba un derecho de los particulares, la sanción variaba en función de la infracción cometida: si se trataba de una revisión injusta se condenaba al discussor al pago de lo que él, a su vez, hubiera hecho pagar a otro; el cobro por la emisión de un recibo llevaba aparejado la pena del cuádruplo. La defraudación al fisco solía ser castigada con la pena del cuádruplo, aunque en ocasiones se añadían las penas correspondientes al delito de concusión o incluso al de sacrilegio. También existían sanciones específicas para otras conductas como la ordenación de revisiones careciendo de habilitación legal, la adquisición de bienes en la provincia en que desempeñan su actividad etc.

VI.Esta figura se mantuvo durante siglos en Bizancio, con la denominación de logoteta, asistiéndose a partir del siglo VII a una diversificación de sus funciones, aunque se siguieron manteniendo las de inspección e intervención fiscal. También se encuentran en Occidente referencias a los discussores tras el 476 d.C. en algunos reinos como el ostrogodo, el franco o el visigodo, destacando en este último los llamados discussores iuramenti, encargados de recibir el juramento de fidelidad al rey. Finalmente habría que indicar que no faltan quienes ven en aquellos funcionarios del Bajo Imperio un antecedente remoto de nuestros Contadores Reales de Rentas. 


\section{REFERENCIAS}

ACCURSIUS, Glossa in Volumen, Corpus Glossatorum Juris Civilis, Augustae Taurinorum, 1969.

AGUDO RUIZ, A., La apelación fiscal en la legislación imperial del Codex Theodosianus, Estudios de Derecho fiscal romano, Dykinson, Madrid, 2016.

AGUSTÍN, A., Constitutionum Graecarum Codicis Justiniani Collectio et Interpretatio, Opera Omnia, vol II, Typis Josephi Rochii, Lucae, 1766.

APARICIO PÉREZ, A., La Hacienda Pública en el Bajo Imperio Romano (años 284 a 476 d. C), Dykinson, Madrid.

BALUZIUS, S., Capitulario Regum Francorum, t. I, Parisiis, 1677.

BALDO DEGLI UBALDI, Commentaria in VII. VIII. IX. X. \& XI. Codicis libros. Summa studio \& labora collatis vetustissimis exemplaribus innumeris proprementis purgata, Lugduni, 1585.

BARBERO, A. -VIGIL, M., La formación del feudalismo en la Península Ibérica, ed. Crítica, Barcelona, 1978.

BARTOLO A SAXO FERRATO, Bartoli commentaria in tres libros codicis, Lugduni, 1549.

BLANCH NOUGUÉS, J.M. Principios básicos de justicia tributaria en la fiscalidad romana, Revista de Derecho Financiero y Hacienda Pública, vol. 48, no 247, 1998, pp. 53-84.

BLUHME, F. H., The Annotated Justinian Code (disponible en http://www.uwyo.edu/lawlib/ blume-justinian/ajc-edition-2/books/).

BREHIER, L., Las instituciones del Imperio Bizantino, trad. J. Almoina, Unión Tipográfica Editorial Hispano Americana, Mexico, 1956.

BOUCHARD, L., Étude sur l'administration des finances de l'Empire Romain dans les dernier temps de son existence, Librairie de Guillaumin, Paris, 1871.

BURY, J.B., The Imperial Administrative System in the Ninth Century: With a Revised Text of Kletorologion of Philotheos, Oxford U.P., 1911.

CALVO, C.P., Consuetudo y mos en la lex Wisigothorum, AHDE, 1984, pp. 209-252.

CASSIODORI, M.A., Opera Omnia in duos tomos distributa, t. I, Rotomani, 1679.

CLAMAGERAN, J., Histoire de l'impot en France, I, Librairie de Guillaumin et Cie., Paris, 1867.

CUJACII, J., Opera ad parisiensem fabrotianam editionem, in XIII t. distributa, t. X, Prati, 1840.

COLLOT, C., La pratique et l'institution du "suffragium" au Bas-Empire, Revue du Histoire et Droit française et étranger, 43, 1965, pp. 185-221.

CUQ, E. L'Examinatio per AEgyptum, Mélanges d'archéologie et d'histoire, t. 13, 1893.

Études d'epigraphie juridique. De quelques inscriptions relatives à l'administration de Dioclétien, Bibliothèque des écoles françaises d'Athènes et de Rome, E. Thorin, Paris, 1881.

DELMAIRE, R. Les responsables des finances impériales au Bas-Empire romain (IVe-VIe S.) Études prosopographiques, 1989. 
DÍAZ MARTÍNEZ, P.C., MARTÍNEZ MAZA, C y SANZ HUESMA, F.J., Hispania tardoantigua y visigoda, ed. Istmo, Madrid, 2007.

DI SEGNI, L. Metropolis and Privincia in Byzantine Palestine, Caesarea Maritima: a retrospective after two millennia, ed. Avner Rabban- Kenneth G. Holum, Leiden-New York-London, 1996.

DU CANGE, Glossarium mediae et infimae latinitatis, t.6, L. Favre, Niort, 1883-1887.

DUMMER SCHEEL, S., La cuestión judía en España durante el reino visigodo. Acusación de conjura contra el monarca bajo el reinado de Égica (694), Revista de Historia y Geografía, 20, 2007, pp. 83-114.

EVANS, J.A.S., The age of Justinian: the circunstances of imperial power, Routledge, London, 1966.

FEHI, Corpus Glossatorum Juris Civilis, t. IV, Lugduni, 1627.

GARZÓN PAREJA, M., Historia de la Hacienda de España, vol. I, Instituto de Estudios fiscales, Madrid, 1984.

GARCÍA DE VALDEAVELANO, L., Curso de Historia de las Instituciones españolas, ed. Revista de Occidente, Madrid, 1973.

GIBERT Y SÁNCHEZ DE LA VEGA, R., Contadores de Hacienda e intervención fiscal en el antiguo régimen castellano, Itinerario histórico de la Intervención General del Estado, Instituto de Estudios Fiscales, Madrid, 1976.

GUILLAND, R., Les logothètes: Ètudes sur l'histoire administrative de l'Empire byzantin, Revue des études byzantines, 29, 1971, pp. 5-115.

GOTHOFREDI, I. Codex Theodosianus, t. IV, Lipsiae, 1740.

HEUMANN-SECKEL, Handlexikon zu den Quellen des römischen Rechts, G. Fischer ed., Jena, 1926.

HUMBERT, G., Saggio sulle finanze e sulla contabilità pubblica presso i romani, trad. it. E. D’Errico, Arnaldo Forni Editore, Bologna, 1977 (ed. facsim. de la de 1886).

IGLESIAS REDONDO, J., La pollicitatio, Derecho romano de obligaciones en homenaje al profesor José Luis Murga Gener, coord. Paricio, ed. Centro de Estudios Ramón Areces, Madrid, 1994.

JONES, A.H.M., The Later Roman Empire (284-602). A social, economic and administrative survey, Basil Blackwell, Oxford, 1964.

The decline of the ancient world, Longman, London, 1975

KAZHDAN, A.P., Oxford Dictionary of Byzantium, Oxford University Press, 2005

LEMKE, L., Bridging Center and Pefiphery: Administrative Communication from Constantine to Justinian, Mohr Siebeck, Tübingen, 2020.

LEOTARD, E., Essai sur la condition des barbares établis dans l'empire romain au quatriéme siécle, Paris, 1873.

MALAVÉ OSUNA, B., Régimen jurídico financiero de las obras públicas en el Derecho romano tardío: los modelos privado y público de financiación, Dykinson, Madrid, 2007. 
MARTÍNEZ VELA, J.A., Varias notas sobre la responsabilidad en Derecho romano del personal encargado de la gestión tributaria, Documento de trabajo Seminario Permanente de Ciencias Sociales, https://www.uclm.es/-/media/Files/C01-Centros/cu-csociales/documentos2012/4.ashx?la=en.

MARTINDALE, J. R., The Prosopography of the Later Roman Empire, vol. II (A.D. 395527), Cambridge U.P., Cambridge, 1980.

M.C., Las tardes de Roque Pio y Don Rufo de Alfarache, Oficina de la viuda de Felipe Teruel, Murcia, 1794.

MINGUEZ, J.M., Sociedad esclavista y sociedad gentilicia, en "Romanización" y "reconquista" en la Península Ibérica, nuevas perspectivas, ed. Hidalgo-Pérez-Hervás, Ed. Universidad de Salamanca, Salamanca, 1998.

MOMMSEN, T., Derecho penal romano, trad. P. Dorado, Temis, Bogotá, 1976.

MONKS, G.R., The Administration of the Privy Purse. An Inquiry into Official Corruption and the Fall of the Roman Empire, Speculum, 32, nº 4, 1957, pp. 748 y ss.

NEVILLE URE, P., Justiniano y su época, trad. Sela Hoffman, Ed. Revista de Derecho Privado, Madrid, 1963.

PAPA, G., Multae gentes... quibus terrae laeticae administrandae sunt. A proposito di CTh. 13.11.10, SDHI, 82, 2016, pp. 177-190.

PHARR, C., The Theodosian Code and novels and the Sirmondian constitution, a translation with commentary, glossary and bibliography, Princeton University Press, 1952.

PÉREZ Y LÓPEZ, A.X., Teatro de la legislación universal de España é Indias, t. VIII, Madrid, 1794.

PÉREZ PRENDES MUÑOZ-ARRACO, Historia del Derecho Español, I, S.P.U. Complutense de Madrid, Madrid, 1999.

PERGAMI, F., L'appello nella legislazione del tardo Imperio, Giuffrè ed., Milano, 2000.

PULLIATI, S., Ricerce sulla legislacione "regionale" dei Giustiniano, Giuffrè, Milano, 1980

QUINTANA ORIVE, E., Régimen jurídico de la responsabilidad de los funcionarios en Derecho romano, 2013, disponible en digitool-uam.greendata.es_(consultado el 22 de noviembre de 2019).

"Ne damna provincialibus infligantur": Algunas observaciones sobre la protección de la población rural en la legislación de época postclásica y justinianea, RGDR, 32, 2019.

RODRÍGUEZ LÓPEZ, R.-GUIJARRO, R., El ius fiscale en el Imperio Protobizantino, RIDROM, no 7, 2011, pp. 424-451.op. ci

SEECK, voz "discussor”, Paulys Realencyclopädie der classischen Altertumswissenschaft, neue Bearbeitung, I-5, Alfred Druckenmüller, Sttutgart, 1970.

SEGUR, L.P., Histoire du Bas-Empire, I, Paris, 1826.

SEMENOV, A., Über Ursprung und Bedeutung des Amtes der Logotheten in Byzanz, Byzantynische Zeitschrift, 19, 1910, pp. 440-449. 
STEIN, R., Studien zur Geschichte des byzantinischen Reiches vornehmlich unter den Kaisern Justinus II u. Tiberius Constantinus, J. B. Metzlersche Verlagsbuchhandlung, Stuttgart, 1919.

STEIN, Histoire du Bas Empire, vol. I, De l'Etat Romain a l'Etat byzantin (284-476), Desclée de Brouwer, Paris, 1959

SZIDAT, J., Terrae Laeticae (Cod. Theod. 13,11,10), Historische Interpretationen. Gerold Waser zum 75. Geburtstag, Weinmann-Walser ed., Franz Steiner Verlag, Stuttgart, 1995.

THOMSON, E. A., Los godos en España, trad. Javier Faci, Alianza Editorial, Madrid, 1971. TORRENT, A., Diccionario de Derecho Romano, Edisofer, Madrid, 2005.

TRISCIUOGLIO, A., Studi sul crimen ambitus in età imperiale, Ledizioni, Milano, 2017.

TWYMAN, B. L, Aetius and the Aristocracy, Zeitschrift für Alte Geschichte, Bd. 19, H. 4, 1970, pp. 480-503.

Recebido em: 22 jul. 2020.

Aceito em: 14 dez. 2020. 